\title{
PTCD1 Is Required for Mitochondrial Oxidative-Phosphorylation: Possible Genetic Association with Alzheimer's Disease
}

\author{
Daniel Fleck, ${ }^{1}$ Lilian Phu, ${ }^{2}$ Erik Verschueren, ${ }^{2}$ Trent Hinkle, ${ }^{2}$ Mike Reichelt, ${ }^{3}$ Tushar Bhangale,${ }^{4}$ Benjamin Haley, ${ }^{5}$ \\ Yuanyuan Wang, ${ }^{1}$ Robert Graham, ${ }^{4}$ Donald S. Kirkpatrick, ${ }^{2}{ }^{\circledR}$ Morgan Sheng, ${ }^{1}$ and Baris Bingol ${ }^{1}$ \\ Departments of ${ }^{1}$ Neuroscience, ${ }^{2}$ Microchemistry, Proteomics, and Lipidomics, ${ }^{3}$ Pathology, ${ }^{4}$ Human Genetics, and ${ }^{5}$ Molecular Biology, Genentech Inc., \\ South San Francisco, California 94080
}

In addition to amyloid- $\beta$ plaques and tau tangles, mitochondrial dysfunction is implicated in the pathology of Alzheimer's disease (AD). Neurons heavily rely on mitochondrial function, and deficits in brain energy metabolism are detected early in AD; however, direct human genetic evidence for mitochondrial involvement in AD pathogenesis is limited. We analyzed whole-exome sequencing data of $4549 \mathrm{AD}$ cases and 3332 age-matched controls and discovered that rare protein altering variants in the gene pentatricopeptide repeat-containing protein 1 (PTCD1) show a trend for enrichment in cases compared with controls. We show here that PTCD1 is required for normal mitochondrial rRNA levels, proper assembly of the mitochondrial ribosome and hence for mitochondrial translation and assembly of the electron transport chain. Loss of PTCD1 function impairs oxidative phosphorylation and forces cells to rely on glycolysis for energy production. Cells expressing the AD-linked variant of PTCD1 fail to sustain energy production under increased metabolic stress. In neurons, reduced PTCD1 expression leads to lower ATP levels and impacts spontaneous synaptic activity. Thus, our study uncovers a possible link between a protein required for mitochondrial function and energy metabolism and AD risk.

Key words: Alzheimer's disease; energy generation; mitochondria; oxidative phosphorylation; PTCD1

Significance Statement

Mitochondria are the main source of cellular energy and mitochondrial dysfunction is implicated in the pathology of Alzheimer's disease $(\mathrm{AD})$ and other neurodegenerative disorders. Here, we identify a variant in the gene PTCD1 that is enriched in AD patients and demonstrate that PTCD1 is required for ATP generation through oxidative phosphorylation. PTCD1 regulates the level of 16S rRNA, the backbone of the mitoribosome, and is essential for mitochondrial translation and assembly of the electron transport chain. Cells expressing the AD-associated variant fail to maintain adequate ATP production during metabolic stress, and reduced PTCD1 activity disrupts neuronal energy homeostasis and dampens spontaneous transmission. Our work provides a mechanistic link between a protein required for mitochondrial function and genetic AD risk.

\section{Introduction}

Alzheimer's disease $(\mathrm{AD})$ is the most common form of dementia and amyloid $\beta(\mathrm{A} \beta)$ plaques and intraneuronal tau tangles are the

Received Jan. 14, 2019; revised March 26, 2019; accepted March 28, 2019.

Author contributions: D.F., M.S., and B.B. designed research; D.F., L.P., and M.R. performed research; D.F., E.V., T.H., M.R., T.B., R.G., and D.S.K. analyzed data; B.H. and Y.W. contributed unpublished reagents/analytic tools; D.F., M.S., and B.B. wrote the paper.

The ADSP study accession number was phs000572.v7.p4. The ADSP is comprised of two AD genetics consortia and three National Human Genome Research Institute funded Large Scale Sequencing and Analysis Centers (LSACS). The two AD genetics consortia are the Alzheimer's Disease Genetics Consortium (ADGC) funded by National Institute on Aging (NIA; U01 AG032984), and the Cohorts for Heart and Aging Research in Genomic Epidemiology (CHARGE) funded by NIA (R01 AG033193), the National Heart, Lung, and Blood Institute (NHLBI), other National Institute of Health $(\mathrm{NIH})$ institutes and other foreign governmental and non-governmental organizations. The Discovery Phase analysis of sequence data are supported through UF1AG047133 (to Drs. Schellenberg, Farrer, Pericak-Vance, Mayeux, and Haines); U01AG049505 to Dr. Seshadri; U01AG049506 to Dr. Boerwinkle; U01AG049507 to Dr. Wijsman; and U01AG049508 to Dr. Goate and the Discovery Extension Phase analysis is supported through U01AG052411 to Dr. Goate, U01AG052410 to Dr. Pericak-Vance and U01 AG052409 to Drs. Seshadri and Fornage. Data generation and harmonization in the Follow-up Phases is supported by U54AG052427 (to Drs. Schellenberg and Wang). defining histopathological hallmarks in the brains of $\mathrm{AD}$ patients. Beyond $\mathrm{A} \beta$ and tau, mounting evidence implicates mitochondrial dysfunction as a mechanism contributing to $\mathrm{AD}$ (Moreira et al., 2010; Swerdlow et al., 2014; Simoncini et al., 2015; Onyango et

The ADGC cohorts include: Adult Changes in Thought, the Alzheimer's Disease Centers (ADCs), the Chicago Health and Aging Project, the Memory and Aging Projec), Mayo Clinic, Mayo Parkinson's Disease controls, University of Miami, the Multi-Institutional Research in Alzheimer's Genetic Epidemiology Stud), the National Cell Repository for Alzheimer's Disease (NCRAD), the National Institute on Aging Late-Onset Alzheimer's Disease Family Study, the Religious Orders Study, the Texas Alzheimer's Research and Care Consortium, Vanderbilt University/Case Western Reserve University, the Washington Heights-Inwood Columbia Aging Project and the Washington University Sequencing Project, the Columbia University Hispanic-Estudio Familiar de Influencia Genetica de Alzheimer, the University of Toronto, and Genetic Differences.

The CHARGE cohorts are supported in part by NHLBl infrastructure Grant HL105756 (Psaty), RC2HL102419 (Boerwinkle), and the neurology working group is supported by the NIA R01 Grant AG033193. The CHARGE cohorts participating in the ADSP include the following: Austrian Stroke Prevention Study (ASPS), ASPS-Family study, and the Prospective Dementia Registry-Austria (ASPS/PRODEM-Aus), the Atherosclerosis Risk in Communities (ARIC) Study, the Cardiovascular Health Study (CHS), the Erasmus Rucphen Family Study (ERF), the Framingham Heart Study (FHS), and the Rotterdam Study. ASPS is funded by the Austrian Science Fond (FWF) Grant P20545-P05 and 
al., 2016). Altered expression of mitochondrial proteins as well as excessive mitochondrial fragmentation have been observed in affected AD brain regions (Hirai et al., 2001; Liang et al., 2008; Wang et al., 2009). Mitochondrial dysfunction increases ROS generation leading to oxidative damage, a key feature that precedes widespread plaque pathology in brains of $\mathrm{AD}$ patients (Nunomura et al., 2001; Williams et al., 2006). In mouse models of $\mathrm{AD}$, oxidative stress can exacerbate amyloid production which in turn impairs mitochondrial function, suggesting a vicious cycle of mitochondrial involvement in pathogenesis (Albrekkan and Kelly-Worden, 2013).

Mitochondria are crucial organelles for energy metabolism and the major source of ATP through oxidative phosphorylation (OXPHOS; Friedman and Nunnari, 2014). The mitochondrial electron transport chain (ETC) that mediates OXPHOS consists

P13180, and the Medical University of Graz. The ASPS-Fam is funded by the Austrian Science Fund (FWF project 1904), the EU Joint Programme-Neurodegenerative Disease Research in frame of the BRIDGET project (Austria, Ministry of Science), and the Medical University of Graz and the Steiermärkische Krankenanstalten Gesellschaft. PRODEM-Austria is supported by the Austrian Research Promotion agency (FFG Project 827462) and by the Austrian National Bank (Anniversary Fund, project 15435. ARIC research is performed as a collaborative study supported by NHLBI contracts (HHSN268201100005C, HHSN268201100006C, HHSN268201100007C, HHSN268201100008C, HHSN268201100009C, HHSN268201100010C, HHSN268201100011C, and HHSN268201100012C). Neurocognitive data in ARIC is collected by U01 2U01HL096812, 2U01HL096814, 2U01HL096899, 2U01HL096902, and 2U01HL096917 from the NIH [NHLBI, National Institute of Neurological Disorders and Stroke (NINDS), NIA, and NIDCD], and with previous brain MRI examinations funded by R01-HL70825 from the NHLBI. CHS research was supported by contracts HHSN268201200036C, HHSN268200800007C, N01HC55222, N01HC85079, N01HC85080, N01HC85081, N01HC85082, N01HC85083, N01HC85086, and Grants U01HL080295 and U01HL130114 from the NHLBI with additional contribution from the NINDS. Additional support was provided by R01AG023629, R01AG15928, and R01AG20098 from the NIA. FHS research is supported by NHLBI contracts N01-HC-25195 and HHSN2682015000011. This study was also supported by additional Grants from the NIA (R01s AG054076, AG049607, and AG033040 and NINDS R01 NS017950). The ERF study as a part of EUROSPAN (European Special Populations Research Network) was supported by European Commission FP6 STRP Grant 018947 (LSHG-CT-2006-01947) and also received funding from the European Community's Seventh Framework Programme (FP7/2007-2013)/Grant agreement HEALTH-F4-2007-201413 by the European Commission under the program "Quality of Life and Management of the Living Resources" of fifth Framework Programme (QLG2-CT-2002-01254). High-throughput analysis of the ERF data was supported by a joint Grant from the Netherlands Organization for Scientific Research and the Russian Foundation for Basic Research (NWO-RFBR 047.017.043). The Rotterdam Study is funded by Erasmus Medical Center and Erasmus University, Rotterdam, the Netherlands Organization for Health Research and Development (ZonMw), the Research Institute for Diseases in the Elderly (RIDE), the Ministry of Education, Culture and Science, the Ministry for Health, Welfare and Sports, the European Commission (DG XII), and the municipality of Rotterdam. Genetic datasets are also supported by the Netherlands Organization of Scientific Research NWO Investments (175.010.2005.011, 911-03-012), the Genetic Laboratory of the Department of Internal Medicine, Erasmus MC, the Research Institute for Diseases in the Elderly (014-93-015; RIDE2), and the Netherlands Genomics Initiative/Netherlands Organization for Scientific Research (NW0) Netherlands Consortium for Healthy Aging, project 050-060-810. All studies are grateful to their participants, faculty, and staff. The content of these manuscripts is solely the responsibility of the authors and does not necessarily represent the official views of the National Institutes of Health or the U.S. Department of Health and Human Services.

The four LSACs are as follows: the Human Genome Sequencing Center at the Baylor College of Medicine (U54 HG003273), the Broad Institute Genome Center (U54HG003067), The American Genome Center at the Uniformed Services University of the Health Sciences (U01AG057659), and the Washington University Genome Institute (U54HG003079).

Biological samples and associated phenotypic data used in primary data analyses were stored at Study Investigators institutions, and at the NCRAD (U24AG021886) at Indiana University funded by the NIA. Associated Phenotypic Data used in primary and secondary data analyses were provided by Study Investigators, the NIA funded ADCs, and the National Alzheimer's Coordinating (enter (U01AG016976), and the National Institute on Aging Genetics of Alzheimer's Disease Data Storage Site (U24AG041689) at the University of Pennsylvania, funded by NIA, and at the Database for Genotypes and Phenotypes (dbGaP) funded by NIH. This research was supported in part by the Intramural Research Program of the NIH, National Library of Medicine. Contributors to the genetic analysis data included study investigators on projects that were individually funded by the NIA, and other NIH institutes, and by private U.S. organizations, or foreign governmental or nongovernmental organizations.

We thank the Alzheimer's Disease Sequencing Project for providing access to the genetic datasets (study accession number: phs000572.v7.p4); (hris Wall for assistance with mitochondrial fractionation, microscopy, and qPCR analysis; Maximilian Adrian for help with Fiji-based image analysis; Flora Hinz for introduction to the IncuCyte platform; Julia Heidmann for assistance with electrophysiology measurements; Audrey Filezac de L'Etang, Annette Vogl, Joanna Lipka, and Borislav Dejanovic for intellectual input and technical assistance.

Conflict of interest: All authors were full-time employees of Genentech, a member of the Roche group, during the course of this study.

Correspondence should be addressed to Baris Bingol at bingol.baris@gene.com or Morgan Sheng at sheng.morgan@gene.com.

https://doi.org/10.1523/JNEUROSCI.0116-19.2019

Copyright $(2019$ the authors of five protein complexes, of which most of the subunits are encoded by nuclear genes. Thirteen ETC proteins, however, are transcribed from the circular mitochondrial genome (mtDNA) which additionally contributes two ribosomal RNAs (12S and 16S rRNAs, backbone of the mitoribosome) and 22 tRNAs to the organelle's own translational system (Rackham et al., 2012; Hällberg and Larsson, 2014).

Consistent with an important role of mitochondria in neuronal health, rare mutations in the mitochondrial genome itself or in genes coding for mitochondrial proteins are associated with neurodegenerative diseases such as Parkinson's disease, Leigh syndrome, and ataxia-neuropathy syndrome (Mattson et al., 2008; Calvo and Mootha, 2010; Tuppen et al., 2010; Johri and Beal, 2012; Koopman et al., 2013). Declining mitochondrial function is considered a general feature of aging and may contribute to lower cellular fitness and the development of agerelated diseases (Sun et al., 2016).

In $\mathrm{AD}$, deficits in brain energy metabolism are detected even before onset of dementia symptoms and mitochondrial dysfunction has been described throughout the course of the disease (Ferreira et al., 2010; Kapogiannis and Mattson, 2011; Kerr et al., 2017). Interestingly, impaired energy metabolism has recently been invoked as a fundamental cellular effect of loss-of-function mutations in TREM2, a microglial cell surface protein strongly linked to AD (Ulland et al., 2017).

$A P O E$ and $C L U$ (Clusterin, ApoJ) are among the strongest risk factors for late-onset, sporadic Alzheimer's disease (LOAD; Bertram et al., 2007) and have likewise been implicated in mitochondrial dysfunction. Although mostly secreted, both ApoE4 and Clusterin reportedly localize to mitochondria and impair ETC function (Chang et al., 2005; Chen et al., 2011) or interact with regulators of apoptosis (Zhang et al., 2005; Trougakos et al., 2009). With regard to genes encoding bona fide mitochondrial proteins, an $\mathrm{AD}$-associated intronic polymorphism in the TOMM40 gene, which encodes the mitochondrial outer membrane import channel, has been described (Roses et al., 2010). However, the direction of the effect of this variant on $\mathrm{AD}$ risk remains unresolved (Cruchaga et al., 2011). Overall, human genetic data directly implicating mitochondrial impairment as risk factor for $\mathrm{AD}$ remains limited.

We analyzed whole-exome sequencing data comparing $\mathrm{AD}$ patients with healthy controls, and found that a coding variant in the gene PTCD1 (pentatricopeptide repeat-containing protein 1; Rackham et al., 2009; Sanchez et al., 2011; Rackham and Filipovska, 2012; Perks et al., 2017, 2018) was associated with AD in multiple cohorts. PTCD1 is an RNA binding protein that localizes to mitochondria and we show that PTCD1 is required for proper assembly of the ETC. Loss of PTCD1 function strongly diminishes energy generation by mitochondria, forcing cells to rely on glycolysis. We describe the molecular mechanism by which PTCD1 is required for OXPHOS. Cells expressing the ADlinked variant of PTCD1 show subtle defects under standard culture conditions but fail to sustain energy production under increased metabolic stress. This study identifies PTCD1 as a protein required for mitochondrial function and provides genetic evidence that a coding variant in PTCD1 may increase susceptibility to $\mathrm{AD}$.

\section{Materials and Methods}

Genetics

The Alzheimer's Disease Sequencing Project (ADSP) Exome sequencing data of short reads was obtained through application to dbGAP (https://dbgap.ncbi.nlm.nih.gov). The study accession number was 
phs000572.v7.p4. Short reads were mapped to the reference genome (build GRCh38) using BWA (Li and Durbin, 2009). Resulting alignments (bam files) were analyzed using GATK (McKenna et al., 2010) for base quality score recalibration, indel realignment, duplicate removal, and SNP and INDEL discovery and joint genotyping across all samples according to GATK Best Practices recommendations (DePristo et al., 2011; Van der Auwera et al., 2013). Variant calling was only performed in the exome capture intervals common to (i.e., the intersection of) the Illumina and Agilent capture platforms used for ADSP samples.

To perform sample QC, first common variants [minor allele frequency $(\mathrm{MAF})>1 \%$ ] were extracted and LD-pruned using PLINK (Purcell et al., 2007). These variants were then used to identify and remove samples based on heterozygosity (6 SD from mean value of inbreeding coefficient) and relatedness, i.e., removal of one sample from the sample pairs with kinship coefficient $k 0$ (probability of zero allele shared identical-bydescent) $>0.4$. Five PCA outlier removal iterations were then performed using EIGNESTRAT (Price et al., 2006) to remove population outliers.

Variant QC (for all variants in the target regions) was performed as follows: genotypes with the GATK quality score $<20$ were set to missing and variants with missing rate $>1 \%$ were removed. Variants with HardyWeinberg test $p<5 \times 10^{-4}$ in the control group were then removed.

Tests for association with case-control status were performed at variant level and gene level (burden test). At variant level, logistic regression of the case-control status was performed on additively coded genotype and first five eigenvector from PCA used as covariates. Significance was assessed by testing the null hypothesis that the genotype effect was zero.

To perform gene-level burden tests, variants were annotated with functional consequences using SnpEff (Cingolani et al., 2012) and those with overall annotation impact of HIGH and MODERATE (for any of the gene isoforms) were identified. Among these, those with MAF $<1 \%$ were identified and used for burden test. For each protein coding gene, a burden score was computed for each individual. Logistic regression of the case-control status on the burden score and first five eigenvectors was then performed and significance was assessed by testing the null hypothesis that the burden score effect was zero.

\section{Cell culture and generation of $\mathrm{KO}$ and rescue cell lines}

HeLa cells were maintained in DMEM supplemented with 10\% FCS (Invitrogen) and transfected using the FuGene HD reagent (Promega) following the manufacturer's instruction. PTCD1 KO HeLa cells were generated through CRISPR/Cas9-mediated gene editing as follows: cells were transfected with the CRISPR/Cas9 construct at $80-90 \%$ density and incubated for $3 \mathrm{~d}$. For single-cell cloning by FACS, the cell layer was washed $2 \times$ with PBS and then incubated with $10 \mathrm{~mm}$ EDTA in PBS for 5 min at RT. Cells were collected, counted and resuspended in FACS buffer (2\% BSA, 5 mm EDTA, 25 mm HEPES in PBS) to reach a final concentration of $5 \times 10^{6}$ cells $/ \mathrm{ml}$. Cells were kept on ice and 1,10 , or 100 cells were sorted into 96-well plates containing $150 \mu \mathrm{l}$ of conditioned culture medium (chilled) per well. Afterward, the plates were centrifuged briefly ( $250 \mathrm{~g}, 2 \mathrm{~min}$ at RT), transferred into a cell culture incubator and singlecell clones were expanded for genotyping.

PTCD1 KO cells stably expressing RFP, PTCD1 WT, or R113W (rescue cell lines) were generated as follows: PTCD1 KO\#1 cells were transfected with rescue constructs $(0.5 \times$ DNA amount recommended by FuGene HD manual) at $60 \%$ density and incubated for $5 \mathrm{~d}$. The long incubation time is necessitated by the slow metabolism of the PTCD1 KO cells. Afterward, cells were split 1:1 into selection media containing 0.5 $\mu \mathrm{g} / \mathrm{ml}$ puromycin (Invitrogen) and maintained for $21 \mathrm{~d}$ (media was exchanged every $3-4 \mathrm{~d}$ and cells were passaged as necessary). Single-cell clones were obtained by limiting dilution of the resistant cell pools into 96-well plates containing conditioned media (with puromycin).

For primary cortical neuron cultures, cortices were isolated from rat embryos on embryonic day 18 or 19 and treated with $0.25 \%$ TrypsinEDTA (Invitrogen) for $25 \mathrm{~min}$ at $37^{\circ} \mathrm{C}$. The tissue was washed $3 \times$ with $\operatorname{DMEM}(10 \%$ FCS $)$ and triturated $20 \times$ with a large bore and $15 \times$ with a small bore glass pipette. Cells were collected by centrifugation $(90 \times g$ for 5 min at RT), resuspended in NbActiv4 (BrainBits) culture medium, counted and plated at an appropriate density into culture vessels coated with poly-D-lysine (PDL) (P7886, Sigma-Aldrich) and laminin (23017-
015, Invitrogen) (coating: $50 \mu \mathrm{g} / \mathrm{ml} \mathrm{MW} 30-70 \mathrm{kDa} P D L$ in $\mathrm{H}_{2} \mathrm{O}$ for $\geq 5$ $\mathrm{h}$ in cell culture incubator, $3 \times$ washes with $\mathrm{H}_{2} \mathrm{O}, 1 \mu \mathrm{g} / \mathrm{ml}$ laminin in $\mathrm{H}_{2} \mathrm{O}$ for $\geq 3 \mathrm{~h}$ as before, 3 washes). Neurons were maintained by replacing $50 \%$ of the medium once a week. For knockdown experiments, neurons were treated with siRNA $(0.5 \mu \mathrm{g} / \mathrm{ml})$ against PTCD1 (ON-TARGETplus SMARTpool L-080501-02-0005, Dharmacon) or control siRNA (ONTARGETplus Non-targeting Pool D-001810-10-05, Dharmacon) packaged into lipid nanoparticles. Nanoparticles were produced using the Neuro9 kit and NanoAssemblr Spark device (Precision NanoSystems) and cultures were treated following the manufacturer's instructions. Knockdown was performed starting at 7-10 DIV and lasted for 4 or $8 \mathrm{~d}$ before analysis. All animal studies were authorized and approved by the Genentech Institutional Animal Care and Use Committee.

\section{Antibodies}

The following primary antibodies were used for immunoblotting and immunocytochemical studies at the indicated dilution:

PTCD1 rabbit polyclonal (HPA020106, HPA047679, Sigma-Aldrich), 1:500; $\beta$-ACTIN HRP conjugate (13E5) rabbit monoclonal (5125, CST), 1:6000; HSP60 (N20) goat polyclonal (sc1052, Santa Cruz Biotechnology), 1:3000; VDAC1 (20B12AF2) mouse monoclonal (ab14734, Abcam), 1:1000; TOM20 (FL-145) rabbit polyclonal (sc11415, Santa Cruz Biotechnology), 1:1000 (1:500 for IF); Total OXPHOS Human WB Antibody Mixture, mouse monoclonal (ab110411, Abcam), 1:1000; Total OXPHOS Rodent WB Antibody Mixture, mouse monoclonal (ab110413, Abcam), 1:1000; TurboGFP rabbit polyclonal (PA5-22688, ThermoFisher Scientific), 1:1000; $\beta$-Tubulin HRP conjugate (9F3) rabbit monoclonal (5346, CST), 1:1000; Histone $\mathrm{H} 3$ rabbit polyclonal (9715, CST), 1:2000; VPS35 mouse monoclonal (ab57632, Abcam), 1:1000; Calreticulin (EPR3924) rabbit monoclonal (GTX62353, Genetex) 1:1000.

The following secondary antibodies were used for immunoblotting and immunocytochemical studies at the indicated dilution: donkey antigoat IgG HRP conjugate (sc2020, Santa Cruz Biotechnology), 1:4000; sheep anti-mouse IgG HRP conjugate (NA931, GE Healthcare), 1:10,000; donkey anti-rabbit IgG HRP conjugate (NA934, GE Healthcare), 1:10,000; donkey anti-rabbit IgG AlexaFluor 488 conjugate (A21206, ThermoFisher Scientific), 1:1000.

\section{Western blotting}

Whole-cell lysates were prepared by resuspending the cells in RIPA buffer [25 mm Tris $\mathrm{HCl}, \mathrm{pH} 7.4,150 \mathrm{~mm} \mathrm{NaCl}, 1 \% \mathrm{NP} 40,1 \% \mathrm{Na}$ deoxycholate, $0.1 \%$ SDS, Benzonase DNase (Sigma-Aldrich), Protease inhibitor (Roche)], vortexing the suspension for $15 \mathrm{~s}$ and incubating the samples on ice for $15 \mathrm{~min}$. Insoluble material was removed through centrifugation $\left(10,000 \times g\right.$ for $10 \mathrm{~min}$ at $\left.4^{\circ} \mathrm{C}\right)$ and the protein concentration in the lysate was determined using the Pierce BCA assay kit (ThermoFisher Scientific). Before SDS-PAGE, sample loading buffer and reducing agent (ThermoFisher Scientific) were added and the samples were diluted to 1 $\mu \mathrm{g} / \mu \mathrm{l}$ final protein concentration. Samples were denatured at $70^{\circ} \mathrm{C}$ for 10 min, except for immunodetection with the Total OXPHOS antibody cocktails, and equal amounts of protein were separated using NuPAGE Novex $4-12 \%$ Bis-Tris protein gels and MOPS or MES buffer ( ThermoFisher Scientific). No reducing agent was added to lysates for immunodetection with the Total OXPHOS antibody mixture and the samples were not heated before electrophoresis.

The Trans-blot Turbo transfer system (Bio-Rad) was used to transfer proteins onto $0.2 \mu \mathrm{m}$ nitrocellulose or PVDF membranes (Bio-Rad). For immunodetection, unspecific antibody binding was reduced by blocking the membranes with 5\% BSA (in PBS) for $1 \mathrm{~h}$ at RT. Membranes were incubated with primary antibodies diluted in blocking buffer overnight at $4^{\circ} \mathrm{C}$ and secondary antibodies (in blocking buffer) were added after three washes with TBS-T buffer (10 mM TRIS pH 8.0, $150 \mathrm{~mm} \mathrm{NaCl}, 0.1 \%$ Tween 20) for $1 \mathrm{~h}$ at RT. Finally, membranes were washed $3 \times$ with TBS-T and Western blots were developed using SuperSignal West Dura or Femto chemiluminescent substrate ( ThermoFisher Scientific) and the ChemiDoc XRS + imaging system (Bio-Rad). Western blot signal intensities were quantified with the Image Lab software (Bio-Rad). 
Immunocytochemistry and image analysis

Cells cultured in 24-well glass bottom plates were washed $3 \times$ with cold PBS and fixed in $4 \%$ PFA (in PBS) for $30 \mathrm{~min}$ at $4^{\circ} \mathrm{C}$. After washing with PBS, permeabilization buffer (0.1\% TX100 in PBS) was added and cells were incubated for $15 \mathrm{~min}$ at RT. Nonspecific interactions were blocked for 30 min at RT (blocking buffer: 5\% BSA in PBS with $100 \mu \mathrm{M}$ digitonin) and primary antibodies were applied (diluted in blocking buffer) overnight at $4^{\circ} \mathrm{C}$. Afterward, cells were washed $3 \times$ with PBS-D (PBS with 100 $\mu \mathrm{M}$ digitonin) and secondary antibodies (diluted in blocking buffer) were added for $1 \mathrm{~h}$ at RT ( protected from light). After three washes with PBS-D, ProLong Gold Antifade Reagent with DAPI (nuclear stain) was added and plates were stored at $4^{\circ} \mathrm{C}$ in the dark until imaging.

Images were acquired using a Leica SP5 laser scanning microscope with a $\times 40 / 1.25$ oil objective at a resolution of $2048 \times 2048$ (pixel size $75.7 \mathrm{~nm}, 2.5 \times$ zoom). At least $14 z$-stacks $(0.5-0.7 \mu \mathrm{m})$ were taken and maximum intensity projections were generated. All images were analyzed using a custom analysis macro in Fiji (Schindelin et al., 2012): first, images were converted to binaries using the "Otsu" (background: dark) thresholding. Noise was removed using the "Remove Outliers" function (radius: 2 pixels, threshold: 50, both bright and dark outliers) and particles were measured using the "Analyze Particles" option. The experimenter was blinded to the experimental conditions during both image acquisition and analysis.

Imaging-based quantification of live and dead cells in primary neuron cultures was done using the IncuCyte Live-Cell Analysis System (Essen BioScience). Neurons were stained with the cell membrane-permeable SYTO 13 (Invitrogen) and the non-permeable IncuCyte Cytotox Red (Essen BioScience) reagent and image analysis was performed using the IncuCyte software.

\section{cDNA and cloning}

To generate the CRISPR/Cas9 constructs for PTCD1 KO in HeLa cells, two guide RNAs (gRNA_L: CCTGATATATTCCAGGCCCTGG, gRNA_R: CCGTGTAGTTGCTCTCCATGGG) were cloned into a vector under the control of $\mathrm{U} 6$ and $\mathrm{H} 1$ promoters, respectively. Additionally, the vector expresses Cas9-HAtag-T2A-EGFP under an EIF1a promoter. The rescue constructs were generated by cloning the human PTCD1 sequence (NM_015545) with or without the R113W variant, including a C-terminal flag tag into a vector derived from the pAAVS1 Dual Promoter Donor Vector (GE602A-1, Genewiz). The final construct expresses PTCD1-Flag under a CMV promoter and GFP-T2Apuromycin under an EF1a promoter.

\section{DNA isolation and genotyping}

Genomic DNA for genotyping of the PTCD1 KO cells and for determining mtDNA versus nDNA amounts was isolated using the DNeasy Blood\&Tissue kit (Qiagen) according to the manufacturer's instructions. For genotyping, the following primers were used in a PCR with the Platinum TaqDNA Polymerase (ThermoFisher Scientific): Seq_F: GGGCCCATACTTGTAACCAC, Seq_R: AAGGCCTTCTTCAGGTA GCC. Afterward, the samples were separated on 1 or $3 \%$ agarose gels (EtBr with TBE buffer; Bio-Rad) for initial screening purposes. The PCR fragments were cloned into the pCR2.1 TOPO vector (ThermoFisher Scientific) for sequencing.

\section{$R N A$ isolation and $q P C R$}

Mitochondrial and cellular RNA was isolated using the miRNeasy Mini kit (Qiagen) according to its manual and $2 \mu \mathrm{g}$ of RNA were used for cDNA synthesis with the iScript cDNA synthesis kit (Bio-Rad). To determine transcript abundance, the cDNA was used as template in a PCR performed on the QuantStudio 7 Flex Real-Time PCR System (Applied Biosystems) using the SsoAdvanced Universal SYBR Green Supermix (Bio-Rad). Transcript levels were normalized to HPRT1 mRNA levels. To determine the relative amounts of mtDNA vs nDNA, isolated DNA was used as template for the qPCR and B2M served as target gene on the nuclear genome. qPCR primer sequences are listed in Table 1. Relative PTCD1 transcript levels after knockdown in rat neuronal cultures were assessed using the TaqMan Gene Expression Cells-to-CT Kit (Ambion) following the manufacturer's instruction. HPRT1 was used as housekeeping gene. TaqMan assays: PTCD1 (Rn01409514_m1, FAM-MGB),
HPRT1 (Rn01527840_m1, VIC-MGB). All experiments were done in technical triplicates.

\section{Live-cell mitochondrial respiration}

Mitochondrial respiration and glycolytic rate were assessed in living cells using the Seahorse XFe24 analyzer platform with the XF Cell Mito Stress Test Kit (Agilent). All experiments were run in technical quadruplicates and set up and analyzed following the manufacturer's instructions. Briefly, $50 \times 10^{3}$ cells/well (in $100 \mu$ l culture medium) were added to the 24-well assay plate on the day before the experiment. Cells were allowed to settle at RT for $30 \mathrm{~min}$ and an additional $100 \mu \mathrm{l}$ of medium were added after $2 \mathrm{~h}$ in the cell culture incubator. For experiments with neurons, assay plates were coated with poly-D-lysine and $80 \times 10^{3}$ dissociated rat neurons were added to each well. Neurons were cultured and treated with siRNA packaged into nanoparticles as described above. One hour before the assay, the culture medium was exchanged with XF Base media assay (10 mm glucose, $2 \mathrm{~mm}$ glutamine, $1 \mathrm{~mm}$ Na pyruvate) and the cells were incubated in a non- $\mathrm{CO}_{2}$ cell culture incubator.

To measure the mitochondrial function, the default assay setup was used and the following compounds were injected sequentially: oligomycin (inhibits complex V), FCCP (uncouples OXPHOS), rotenone and antimycin (inhibit complex I and III, respectively), and 2-deoxy-glucose (blocks glycolysis). All inhibitors were used at a final concentration of 1 $\mu \mathrm{M}$, except 2-deoxy-glucose, which was used at $50 \mathrm{~mm}$. After the assay, the cells were washed with PBS, lysed in RIPA buffer $25 \mathrm{~mm}$ Tris $\mathrm{HCl}$, pH7.4, 150 mм NaCl, 1\% NP40, 1\% Na deoxycholate, 0.1\% SDS, Benzonase DNase (Sigma-Aldrich), Protease inhibitor (Roche)] and the protein concentration was determined using the Pierce BCA assay kit (ThermoFisher Scientific). Rates of oxygen consumption (OCR) and extracellular acidification (ECAR) were normalized to the amount of protein/well and the lysate was used for Western blotting.

\section{Quantitation of cellular ATP concentration}

The cellular ATP concentration was determined using the CellTiter-Glo Luminescent Cell Viability Assay (Promega) according to the manufacturer's instructions. One $\times 10^{4}$ cells/well were cultured in 96-well plates overnight and, $5 \mathrm{~h}$ before the first assay time point, were washed $2 \times$ with PBS, $100 \mu \mathrm{l}$ of the respective medium were added and the cells were returned to the cell culture incubator. All media were based on the no glucose DMEM medium (11966025, Invitrogen) and contained 10\% FCS, $4 \mathrm{~mm}$ glutamine, $1 \mathrm{~mm}$ pyruvate, and $25 \mathrm{~mm}$ glucose (glucose medium) or $10 \mathrm{~mm}$ galactose (galactose medium) or $10 \mathrm{~mm}$ acetoacetate (acetoacetate medium). For quantitation, an ATP (Sigma-Aldrich) standard curve was generated and all measurements were done in technical triplicates.

\section{Mass spectrometry analysis}

Preparation of whole-cell and mitochondria fractions. The method used for preparing mitochondrial fractions is based on protocols published previously (Clayton and Shadel, 2014a,b). All steps were performed on ice, all centrifugations at $4^{\circ} \mathrm{C}$ and all glassware was precooled. Cell pellets from $8 \times 15 \mathrm{~cm}$ culture dishes (per sample) were resuspended in $11 \mathrm{ml}$ of cold RSB hypo buffer (10 mm NaCl, $1.5 \mathrm{~mm} \mathrm{MgCl}_{2}, 10 \mathrm{~mm}$ Tris- $\mathrm{HCl} \mathrm{pH}$ 7.5, cOmplete mini EDTA-free protease inhibitor and PhosSTOP phosphatase inhibitor; both Roche) and incubated on ice for $10 \mathrm{~min}$. Swollen cells were homogenized using a $15 \mathrm{ml}$ Dounce homogenizer (60-70 strokes, tight fitting pestle) and successful homogenization was confirmed with a phase-contrast microscope. After saving an aliquot as "whole-cell lysate", $2.5 \times$ mass spectrometry (MS) buffer (in mM: 525 mannitol, 175 sucrose, 12.5 Tris- $\mathrm{HCl}, \mathrm{pH} 7.5,2.5$ EDTA with proteases and phosphatase inhibitors) was added to the lysate to a final concentration of $1 \times$ and the lysate was centrifuged for $5 \mathrm{~min}$ at $1300 \times g$ to remove intact cells, debris, and nuclei. The supernatant was transferred to a new tube and the centrifugation was repeated $2 \times$.

Mitochondria were pelleted at 15,000 $\times g$ for $15 \mathrm{~min}$ (visible as brown to white pellet), resuspended in $3 \mathrm{ml} 1 \times$ MS buffer and layered on top of a discontinuous sucrose gradient $(1.5 \mathrm{M}$ and $1.0 \mathrm{~m}$ sucrose in $10 \mathrm{~mm}$ Tris- $\mathrm{HCl}, \mathrm{pH} 7.5,1 \mathrm{~mm}$ EDTA). The gradient was centrifuged at $60 \times 10^{3}$ $\times g$ for $40 \mathrm{~min}$ in an ultracentrifuge (SW40Ti or SW41Ti rotor) and the mitochondrial fraction was collected from the interface between the two 
Table 1. List of primers used for qPCR (based on Rackham et al., 2009)

\begin{tabular}{|c|c|c|c|c|c|}
\hline Primer name & Sequence & $\begin{array}{l}\text { PCR product } \\
\text { size, bp }\end{array}$ & Primer name & Sequence & $\begin{array}{l}\text { PCR product } \\
\text { size, bp }\end{array}$ \\
\hline \multicolumn{2}{|c|}{ QPCR primers for mitochondrial RNAs (human) } & & ND5fwdJ & СТССАСТССАТСАТСАССТ & 239 \\
\hline ND1fwd & ATGGCCAACCTCCTACTCCT & 215 & NDGrevJ & AGAGGGGTCAGGGTTGATTC & \\
\hline ND2fwd & AAGCAACCGCATCCATAATC & 155 & CytBrevJ & ATCATGGGGAGATGTTGGAT & \\
\hline ND2rev & TCAGAAGTGAAAGGGGGCTA & & \multicolumn{2}{|c|}{ qPCR primers for housekeeping genes (human) } & \\
\hline Co1fwd & ACGTTGTAGCCCACTTCCAC & 222 & HPRT1fwd & GTGATAGATCCATTCCTATGACTGTAG & 135 \\
\hline CO2rev & TAAAGGATGCGTAGGGATGG & & B2Mrev & TCTCTGCTCCCCACCTCTAAGT & \\
\hline ATP8fwd & ATGGCCCACCATAATTACCC & 170 & \multicolumn{2}{|c|}{ qPCR primers for mitochondrial RNAs (rat) } & \\
\hline ATP8rev & GCAATGAATGAAGCGAACAG & & RNR1fwd & AAAGGACTTGGCGGTACTTTAT & 113 \\
\hline ATP6fwd & TATTGATCCCCACCTCCAAA & 233 & RNR1rev & GCTGAAGATGGCGGTATATAGG & \\
\hline ATP6rev & GATGGCCATGGCTAGGTTTA & & RNR2fwd & СTAATCCTAGCCCTACAACCAAC & 129 \\
\hline co3fwd & ACACCACCTGTCCAAAAAGG & 233 & RNR2rev & ССATTCCCTTGCGGTACTT & \\
\hline ND4Lrev & GGCCATATGTGTTGGAGATTG & & RNA19rev & AAGATTGGGATTAGGAGTGTTAGG & \\
\hline ND4fwd & ССTGACTCCTACCCCTCACA & 239 & \multicolumn{2}{|c|}{ qPCR primers for housekeeping genes (rat) } & \\
\hline ND4rev & GAAGTATGTGCCTGCGTTCA & & HPRT1fwd & Purchased, Integrated DNA Technologies & \\
\hline ND5fwd & ACATCTGTACCCACGCCTTC & 208 & + rev Mix & (Rn.PT0.39a0.22214832) & \\
\hline
\end{tabular}

Table 1. Continued

TGATTGTTAGCGGTGTGGTC

ND6rev CCACAGCACCAATCCTACCT

CYBfwd TATCCGCCATCCCATACATT

CYBrev GGTGATTCCTAGGGGGTTGT

RNR1fwd CCAGAACACTACGAGCCACA

RNR1rev CACCTCATGGGCTACACCTT

RNR2fWd GCTAAACCTAGCCCCAAACC

RNR2rev TTGGCTCTCCTTGCAAAGTT

AATAAATCATAAGGCAGAGCCCGGTAATCGCA

tRNALuurR AATAAATCATAATGTTAAGAAGAGGAATTGAACCTCTGACTGT

tRNALCunF AATAAATCATAAATCCATTGGTCTTAGGCCCC

tRNALCUnR AATAAATCATAAACTTTTATTTGGAGTTGCACCA

qPCR primers for junctions between mitochondrial RNAs (human)

tRNAFfwdJ CTCCTCAAAGCAATACACTGAAA

RNR1revJ CTAAGAGCTAATAGAAAGGCTAGGA

RNR1fwdJ CCGTCACCCTCCTCAAGTAT

RNR2revJ GGGTTTGGGGCTAGGTTTAG

RNA19fwd CCTCCCTGTACGAAAGGACA

RNA19rev AGGAATGCCATTGCGATTAG

ND1fwdJ TTCCTACCACTCACCCTAGCA

ND2revJ GATGAGTGTGCCTGCAAAGA

ND2fwdJ ACACTCATCGCCCTTACCAC

tRNAArevJ GTTGATGCAGAGTGGGGTTT

tRNACYfwdJ ATCACCTCGGAGCTGGTAAA

C01revJ TGCCTAGGACTCCAGCTCAT

C01fwdJ CCACCCTACCACACATTCG

CO2revJ GAGGGCGTGATCATGAAAG

CO2fwdJ CATGCCCATCGTCCTAGAAT

ATP8revJ TATGGTGGGCCATACGGTAG

ATPSfwdJ CACCTACCTCCCTCACCAAA

ATP8 - 6rev GGGATCAATAGAGGGGGAAA

ATPGfwdJ CCTCTACCTGCACGACAACA

C03revJ GAGGAGCGTTATGGAGTGGA

C03fwdJ CGCCTGATACTGGCATTTTG

ND3revJ TGTAGCCGTTGAGTTGTGGT

ND3fwdJ GCCCTAAGTCTGGCCTATGA

ND4LrevJ GGGAGGATATGAGGTGTGAGC

ND4LffwdJ ACACCCACTCCCTCTTAGCC

ND4revJ AATTAGGCTGTGGGTGGTTG

ND4fwdJ ACACCTATCCCCCATTCTCC

ND5revJ TAAAGGTGGATGCGACAATG

221

188

216 sucrose layers. The sucrose in the isolated fraction was diluted to $0.25 \mathrm{M}$ by slowly (dropwise) adding dilution buffer ( $5 \mathrm{~mm}$ Tris- $\mathrm{HCl}, \mathrm{pH} 7.5,1$ mM EDTA) and the mitochondria were recovered for $15 \mathrm{~min}$ at 15,000 $\times$ $g$. After one wash with $1 \times$ MS buffer, the mitochondria were lysed in RIPA buffer (25 mm Tris HCl, pH7.4, $150 \mathrm{~mm} \mathrm{NaCl}, 1 \%$ NP40, $1 \% \mathrm{Na}$ deoxycholate, $0.1 \%$ SDS) for $30 \mathrm{~min}$ on ice, insoluble material was removed by centrifugation $(20,000 \times g$ for $10 \mathrm{~min})$ and mitochondrial lysates were stored at $-80^{\circ} \mathrm{C}$.

Preparation of samples for mass spectrometry analysis. Mass spectrometry analysis was performed using three independent biological replicates. A total of $6 \mu \mathrm{g}$ of whole-cell or mitochondrial lysate were reduced with DTT $(10 \mathrm{~mm})$ at $70^{\circ} \mathrm{C}$ for $10 \mathrm{~min}$. Alkylation was done by adding IAA (final concentration $20 \mathrm{~mm}$ ) and incubating the sample for $30 \mathrm{~min}$ at RT in the dark. Afterward, sample loading buffer was added and the entire sample was separated via SDS-PAGE. Each lane of the Coomassie stained gel was subjected to in gel trypsin digestion as previously described (Zuchero et al., 2016). Briefly, gel lanes were cut from top to bottom into nine sections. Individual sections were then further chopped into $1 \mathrm{~mm}$ cubes and placed into microcentrifuge tubes, and de-stained by serial washes with $10 \times$ gel volumes of $50 \mathrm{~mm}$ ammonium bicarbonate $/ 50 \%$ acetonitrile, $\mathrm{pH} 8.0$, and $10 \times$ gel volumes of $100 \%$ acetonitrile for 15 min each. Gel pieces were then washed and dehydrated with an additional $10 \times$ gel volume of $100 \%$ acetonitrile. Trypsin solution was prepared at a concentration of $10 \mathrm{ng} / \mu \mathrm{l}$ trypsin in $50 \mathrm{~mm}$ ammonium bicarbonate, $\mathrm{pH} 8.0$, and added to the gel pieces on ice. Gel pieces were incubated in this trypsin solution for $1 \mathrm{~h}$ and then transferred to a $37^{\circ} \mathrm{C}$ water bath for overnight trypsin digestion. Digested peptides were collected and combined with an additional elution performed with $2 \times$ gel volumes of $50 \%$ acetonitrile $/ 5 \%$ formic acid. Samples were dried to completion in a SpeedVac ( ThermoFisher Scientific) and then resuspended in $2 \%$ acetonitrile $/ 0.1 \%$ formic acid before mass spectrometric analysis.

Mass spectrometry analysis. Using a NanoAcquity UPLC (Waters), reconstituted peptides were loaded onto a $0.1 \mathrm{~mm} \times 100 \mathrm{~cm} \mathrm{C18} \mathrm{column}$ packed with $1.7 \mathrm{~mm} \mathrm{BEH}-130$ resin at a flow rate of $1.5 \mu \mathrm{l} / \mathrm{min}$ over a span of $10 \mathrm{~min}$. Loaded peptides were then separated using a two-stage linear gradient where solvent B (98\% acetonitrile/2\% water/0.1\% formic acid) ramped from 5 to $25 \%$ over $35 \mathrm{~min}$ and then from 25 to $50 \%$ over 2 min. Buffer A was composed of $98 \%$ water $/ 2 \%$ acetonitrile $/ 0.1 \%$ formic acid. Peptides were introduced to an Orbitrap Elite ( ThermoFisher Scientific) mass spectrometer using the ADVANCE Captive Spray Ionization source (Michrom-Bruker). Orbitrap full-MS (MS1) spectra were 
collected at 60,000 resolution and used to trigger data-dependent MS2 scans in the linear ion trap on the top 15 most intense ions.

MS2 spectra were searched using MaxQuant v1.6.26 (Cox and Mann, 2008) against a database of reviewed human proteins from UniProt (downloaded May, 2018), common contaminants and the reversed version of each sequence. Searches were performed with $20 \mathrm{ppm}$ and $0.5 \mathrm{Da}$ mass tolerances for precursor ions and fragment ions, respectively. Trypsin specificity was enforced and up to 2 missed cleavages were permitted. Carbamidomethylated cysteine was considered as a fixed modification $(+57.0215 \mathrm{Da})$ and oxidized methionine $(+15.9949 \mathrm{Da})$ or protein $\mathrm{N}$-terminal acetylation $(+42.0105 \mathrm{Da})$ as variable modifications. Peptide assignments were first filtered to a $1 \%$ false discovery rate (FDR) at the peptide level and subsequently to a $1 \%$ FDR at the protein level. All peptides were quantified in MaxQuant by the label-free quant (LFQ) algorithm, with the match between runs option enabled, for each of the three replicate sets separately and post-processed with a custom R script. Briefly, all match between run events (MATCH-MSMS) with a quality score below the fifth percentile, per replicate, were filtered out. All remaining missing values were imputed by the first percentile (.001) per fraction. LFQ intensities for peptides that were identified across multiple gel fractions, within a single lane, were summarized by their maximum LFQ intensity value. Then, for each identified protein we fit a model in MSstats v3.7.1 (Choi et al., 2014) using the Tukey Median Polish summarization method and equalizeMedians normalization option. Within MSstats, the estimated fold-change and adjusted $p$-value (BenjaminiHochberg correction) between wild-type (WT) and PTCD1 knock-out (KO) was computed for the whole-cell lysate and mitochondrial fractions separately.

Proteins with a $\log 2$ fold-change $>2.0$ and an adjusted $p$ value of $<0.05$ were considered to be differentially abundant in WT and KO mitochondrial fractions. In whole-cell lysates, only $6 \%$ of proteins exhibited a $\log 2$ fold-change $>1.5$ between WT and PTCD1 KO. Therefore, to perform an overrepresentation analysis, this less stringent cutoff was chosen for the whole-cell lysate analysis. The PANTHER (Mi et al., 2017) overrepresentation tool with default settings was used to identify biological processes and protein classes changed in whole-cell lysates from WT and KO cells. All mass spectrometry Raw files, as well as the MaxQuant result files, were uploaded on the Massive data repository under dataset identifier MSV000083232 and can be downloaded directly from ftp://massive.ucsd.edu/MSV000083232.

\section{A $\beta$ immunoassay}

The concentration of $\mathrm{A} \beta 40$ peptides in the supernatant of primary neuron cultures was measured by sandwich ELISA as described previously (Jonsson et al., 2012): a rabbit polyclonal antibody specific for the $\mathrm{A} \beta 40$ C-terminus (AB5737, Millipore) was coated onto ELISA plates and a biotinylated anti-A $\beta$ monoclonal antibody ( $6 \mathrm{E} 10$, Covance) was used for detection.

\section{Electrophysiology}

Spontaneous neuronal activity was measured using the Maestro Apex platform (Axion Biosystems). Cyto View 48 well microelectrode array (MEA) plates (16 electrodes/well) were coated with PDL and $1 \times 10^{5}$ neurons/well were plated, cultured, and treated with nanoparticles as described. Before recording, the plates were transferred to the Maestro system $\left(37^{\circ} \mathrm{C}, 5 \% \mathrm{CO}_{2}\right)$ and allowed to equilibrate for $30 \mathrm{~min}$. Spontaneous activity was recorded for $10 \mathrm{~min}$ at $12.5 \mathrm{kHz}$ sampling frequency using the integrated software package (AxIS v2.4.2.12) in neural broadband mode. The threshold for spike detection for each electrode was set to $6 \times$ the SD of the voltage and only electrodes with $>5$ spikes $/$ min were considered active. Experiments were done in technical triplicates and spike trains were analyzed using the AxIS software package.

Transmission electron microscopy

The cell layer of an almost confluent $10 \mathrm{~cm}$ culture dish was washed $1 \times$ with PBS and fixed in 1/2 Karnovsky's fixative (2\% paraformaldehyde, $2.5 \%$ glutaraldehyde in $0.1 \mathrm{~m}$ sodium cacodylate buffer, $\mathrm{pH}$ 7.2). The cells were then postfixed in $1 \%$ reduced osmium tetroxide, stained "en block" with $0.5 \%$ uranyl acetate and gently harvested and pelleted. Dehydration of samples was through an ascending series of ethanol, followed by two propylene oxide washes. The samples were finally embedded in Eponate 12 (Ted Pella) and cured at $65^{\circ} \mathrm{C}$ for $2 \mathrm{~d}$. Sections of $1 \mu \mathrm{m}$ were used for $\mathrm{T}$-Blue light microscopic evaluation and $80 \mathrm{~nm}$ ultrathin sections (counterstained with lead citrate) were prepared for TEM. Images were acquired at $2000-8000 \times$ with a JEOL JEM-1400 (80 keV) and a Gatan Ultrascan 1000 CCD camera. Approximately 20 cells per sample were randomly selected and analyzed. The experimenter was blinded to the experimental conditions.

\section{Experimental design and statistical analysis}

Statistical analysis was performed using GraphPad Prism6. The applied statistical tests, post hoc analyses, sample sizes $(n)$, and number of independent experiments are defined in each figure legend. A $p$ value $<0.05$ was considered statistically significant in all analyses. Sample size was chosen based on similar experiments in previously published studies. Unless otherwise noted, all data are presented as mean \pm SEM and whenever possible are shown as scatter blots with bar graphs to visualize single data points. Details for the statistical analysis of genetic and mass spectrometry data are given in the respective method sections.

\section{Data availability}

All data generated and analyzed during this study are included in this published article (and its supplement). Exome sequence data are available at https://dss.niagads.org/studies/alzheimers-disease-sequencingproject-adsp/ and the microarray data have been published before (Sims et al., 2017). Mass spectrometry data are available at the massive data repository at ftp://massive.ucsd.edu/MSV000083232. Primary data files are available from the corresponding author on reasonable request.

\section{Results}

\section{PTCD1 coding variants and susceptibility to $A D$}

To identify novel AD risk alleles in genes encoding mitochondrial proteins, we obtained whole-exome sequence data for $4549 \mathrm{AD}$ cases and 3332 age-matched controls generated by ADSP available from dbGaP (https://dss.niagads.org/studies/alzheimersdisease-sequencing-project-adsp/). We analyzed the data to perform variant calling followed by a genome-wide variant gene burden analysis. This approach aggregates rare (minor allele frequency $<1 \%$ ) coding variants in a gene to compute a gene-level burden score for each sample and correlates it with the disease status.

After ranking the genes by their burden test $p$-value for association with AD, PTCD1 was among the top 100 of 17,000 genes analyzed. PTCD1 was among the top 10 of 1158 genes that encode mitochondrial proteins (based on MitoCarta 2.0) and the top gene among those in which rare alleles increase disease risk. Burden testing involved analysis of 96 rare coding variants in PTCD1 and revealed that these variants in aggregate are 1.4-fold more frequent in our $\mathrm{AD}$ cohort compared with healthy controls $(\mathrm{OR}=1.4, p=0.0051$, not adjusted for multiple testing, aggregate frequency: case $=4.7 \%$, control $=3.8 \%$ ). Next, we sought to determine whether specific variants were driving the disease association and discovered that a SNP (rs35556439) in exon 2 of $P T C D 1$ was most robustly linked with $\mathrm{AD}(\mathrm{OR}=2.3, p=0.0024$; Fig. 1A). To confirm the association of rs35556439 with AD using independent genetic data, we examined exome array datasets derived from three independent cohorts of combined 15,074 AD cases and 34,419 age-matched controls (Sims et al., 2017). In all three cohorts, the missense variant rs35556439 was consistently enriched in the patient population compared with controls (combined: $\mathrm{OR}=1.6, p=4.3 \times 10^{-6}$; Fig. $1 A$ ).

The SNP rs35556439 alters an arginine $(\mathrm{R})$ residue at position 113 of PTCD1 to a tryptophan (W), replacing the positive charge at this location with a nonpolar, aromatic amino acid. Because the structure of PTCD1 has not been solved, it is not possible to 
A

Gene: PTCD1 SNP: rs35556439 Effect: R113W

\begin{tabular}{|c|c|c|c|c|c|c|c|}
\hline Data set & Cohort & $\begin{array}{l}\text { Odds } \\
\text { Ratio }\end{array}$ & $\mathrm{p}$-Value & $\begin{array}{c}\text { Case } \\
\text { Frequency }\end{array}$ & $\begin{array}{c}\text { Control } \\
\text { Frequency }\end{array}$ & $\begin{array}{c}\text { Case } \\
\text { Genotype } \\
\text { Counts }\end{array}$ & $\begin{array}{l}\text { Control } \\
\text { Genotype } \\
\text { Counts }\end{array}$ \\
\hline Exome sequencing & ADSP & 2.3 & $2.4 \mathrm{E}-03$ & 7.0E-03 & $2.9 \mathrm{E}-03$ & $0 / 64 / 4485$ & $0 / 19 / 3313$ \\
\hline \multirow{4}{*}{ Exome microarray } & ADGC & 1.8 & 1.7E-06 & 7.5E-03 & $4.2 \mathrm{E}-03$ & 0/118/7748 & 0/198/23401 \\
\hline & GERAD & 1.1 & $7.8 \mathrm{E}-01$ & 4.7E-03 & $4.2 \mathrm{E}-03$ & $0 / 56 / 5944$ & $0 / 25 / 2949$ \\
\hline & CHARGE & 1.7 & $1.8 \mathrm{E}-01$ & $3.2 \mathrm{E}-03$ & $2.0 \mathrm{E}-03$ & $0 / 9 / 1382$ & 0/32/8069 \\
\hline & COMBINED & 1.6 & 4.3E-06 & $6.0 \mathrm{E}-03$ & 3.7E-03 & $0 / 183 / 15074$ & $0 / 255 / 34419$ \\
\hline
\end{tabular}

B

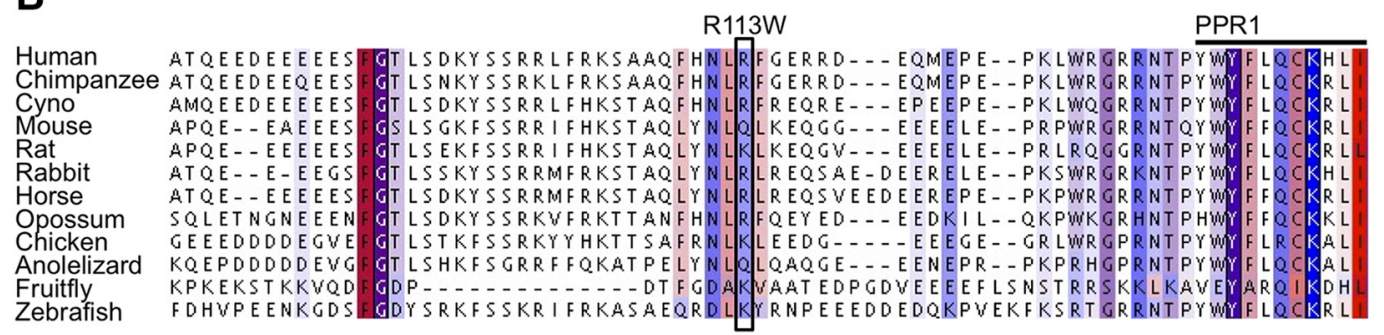

C

PTCD1 locus

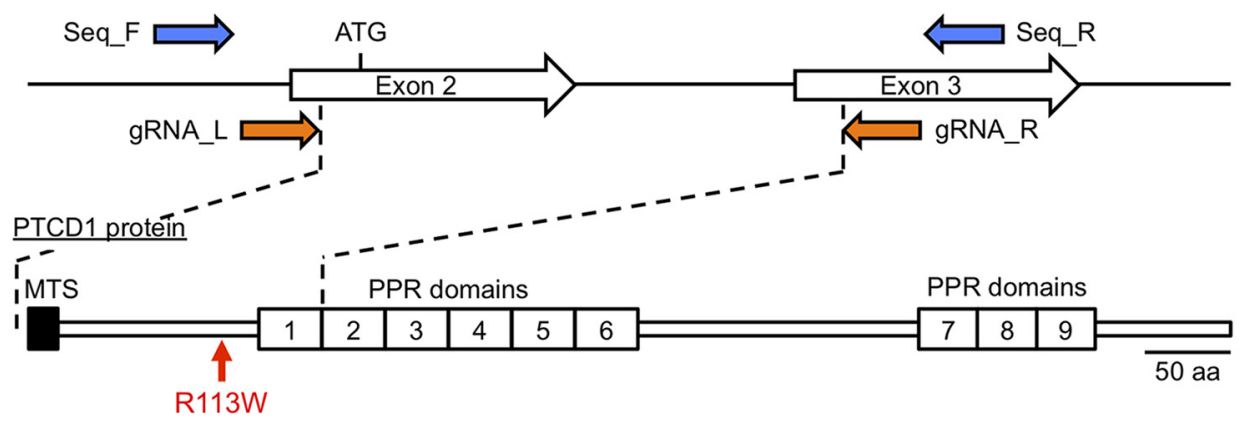

D

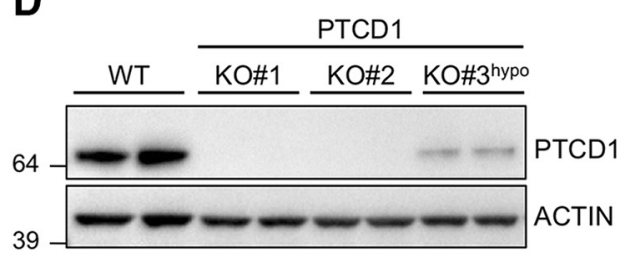

E

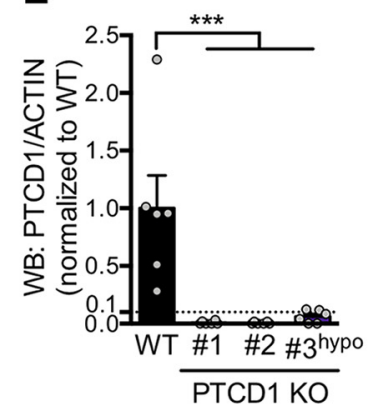

Figure 1. Identification of R113W PTCD1 as variant with increased risk of late-onset AD and generation of PTCD1 K0 HeLa cell line. A, AD association results for R113W in whole-exome sequencing data (top) and exome microarray data of three independent cohorts (bottom, gray). B, PTCD1 sequence alignment (Clustal Omega) upstream and downstream of R113 across different species. Color scheme, hydrophobicity: red, most hydrophobic; blue, most hydrophilic. C, Schematic overview of PTCD1 genetic locus and protein. Positions of gRNAs (orange arrows) for CRISPR/Cas9-mediated knock-out and primers (blue arrows) for PCR-based knock-out identification are given. Dashed lines delimit the portion of PTCD1 deleted in the knock-out. The location of R113W is indicated (red arrow). D, E, Confirmation of HeLa PTCD1 K0 clones 1, 2, and of hypomorphic clone 3 hypo . D, PTCD1 protein was detected by Western blotting of cell lysates from WT HeLa cells and KO clones KO\#1-\#3 ${ }^{\text {hypo }}$. $E$, Protein levels were quantified and normalized to WT. ACTIN was used as loading control. Data for quantifications from six independent experiments and presented as mean \pm SEM ${ }^{* * *} p \leq 0.001$ between cell lines by one-way ANOVA with post hoc Tukey's multiple-comparison test. For confirmation of HeLa PTCD1 KO cell clones by PCR and sequencing, see Figure 1-1, available at https://doi.org/10.1523/JNEUROSCI.0116-19.2019.f1-1. 
model the effects of R113W on overall protein structure. However, a positively charged/polar residue at position 113, lying between two hydrophobic residues at 112 and 114, resides within a conserved stretch of amino acids in PTCD1 from different species (Fig. 1B).

Together our human genetic analysis suggests that variants in PTCD1, particularly R113W, likely increase the risk of AD.

\section{Generation of PTCD1 KO cell line}

To investigate the cellular function of PTCD1, we generated cells lacking PTCD1 using CRISPR/Cas9-mediated genome editing. We designed paired gRNAs targeting the $5^{\prime}$ coding region of the PTCD1 gene (Fig. 1C). Successful editing removes $1.9 \mathrm{~kb}$ of the $5^{\prime}$ coding region of $P T C D 1$, including the start codon in exon 2 and the first PPR domain in exon 3. Following transfection of gRNAs and Cas9, single-cell clones were obtained and screened for WT or KO of PTCD1 by PCR (Fig. 1-1 A, available at https://doi.org/ 10.1523/JNEUROSCI.0116-19.2019.f1-1). Successful KO was further confirmed in selected clones by Western blot for PTCD1 (Fig. $1 D$ ) and DNA sequencing (Fig. 1-1B, available at https:// doi.org/10.1523/JNEUROSCI.0116-19.2019.f1-1). Eventually we selected for further studies two KO cell clones (named KO\#1,

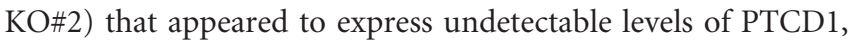
and a third clone that retained very low $(<10 \%$ of WT) amounts of PTCD1 expression (KO\#3 hypomorph, KO\#3 ${ }^{\text {hypo }}$; Fig. $1 D, E$ ).

\section{Lack of PTCD1 abolishes cellular oxygen consumption and shifts energy metabolism to glycolysis}

The mitochondrial genome encodes 13 of 67 essential subunits of the ETC, the primary site of energy generation through OXPHOS. Because PTCD1 is a mitochondrial protein implicated in the regulation of mitochondrial transcription (Rackham and Filipovska, 2012), we first investigated the role of PTCD1 in cellular energy metabolism (Fig. 2). Using the Seahorse analyzer, we measured the OCR and ECAR in cultures of live WT versus PTCD1 KO cells (Fig. 2A,B), because these parameters are correlated with the extent of cellular ATP generation through OXPHOS and glycolysis, respectively. Remarkably, basal oxygen consumption was abolished in PTCD1 KO\#1 and KO\#2 cells that lack PTCD1 and was dramatically reduced in $\mathrm{KO} \# 3^{\text {hypo }}$ cells with small amounts of residual PTCD1 expression (Fig. 2C). Blocking OXPHOS (complex V) and mitochondrial respiration (complexes I and III) in KO\#1 or KO\#2 cells did not further decrease oxygen consumption indicating a complete lack of ETC activity in cells lacking PTCD1 (Fig. 2-1 A, available at https://doi.org/ 10.1523/JNEUROSCI.0116-19.2019.f2-1).

Maximal mitochondrial respiration can be induced by uncoupling the ETC (with FCCP) and allows an estimation of the spare respiratory capacity, i.e., the ability of cells to boost respiration and ATP generation above baseline to meet increased energy demands. When challenged with FCCP, PTCD1-lacking cells (KO\#1, KO\#2) were unable to achieve OCR levels above baseline indicating no respiratory reserve. This phenotype was less pronounced in $\mathrm{KO} \# 3^{\text {hypo }}$ cells (Fig. $2 A, C, D$ ).

Another principal source of energy, independent of mitochondria, is ATP generation through glycolysis. WT cells responded to blocked mitochondrial respiration (treatment with oligomycin) by raising their glycolytic flux (Fig. $2 B, E$ ), a phenomenon called glycolytic reserve (Fig. $2 F$ ). By contrast, PTCD1lacking cells showed a high level of glycolysis already at baseline that did not further increase after blocking OXPHOS (Fig. $2 B, E, F)$. The total glycolytic capacity, i.e., maximal glycolytic rate, was not changed in $\mathrm{KO}$ cells and there was no difference in
ECAR when glycolysis was blocked (Fig. 2-1 B, available at https:// doi.org/10.1523/JNEUROSCI.0116-19.2019.f2-1). Together this indicates that cells without PTCD1 rely on glycolysis rather than OXPHOS for energy generation (Fig. $2 G$ ), a metabolic state reminiscent of the Warburg effect in tumor cells.

To confirm the strong dependency of PTCD1 KO cells on glycolysis and their inability to sustain sufficient energy generation by OXPHOS, we substituted the usual glucose in the culture medium with galactose or acetoacetate and measured cellular ATP levels at different time points. Galactose and acetoacetate prompt cells to rely on OXPHOS instead of glycolysis for energy generation, galactose by slowing down glycolysis (Aguer et al., 2011) and acetoacetate by being a substrate for OXPHOS but not for glycolysis. After $72 \mathrm{~h}$ in galactose medium WT cells were able to maintain a steady ATP concentration whereas ATP levels in PTCD1 KO cells declined by $\sim 90 \%$ after 24 h (Fig. $2 H$ ). Likewise, in acetoacetate containing medium PTCD1 KO cells retained only $\sim 10 \%$ ATP after $24 \mathrm{~h}$ whereas ATP levels in WT cells were at $\sim 100, \sim 60$, and $\sim 20 \%$ after 24,48 , and $72 \mathrm{~h}$, respectively. Similar to the results of the Seahorse assay, PTCD1 KO\#3 ${ }^{\text {hypo }}$ cells showed an intermediate phenotype in both media when compared with WT and KO\#1 or \#2 cells. In summary our data show that OXPHOS is totally dependent on the mitochondrial protein PTCD1, and cells without PTCD1 rely on glycolysis for energy generation.

\section{Cells without PTCD1 maintain mitochondrial content but mitochondria are fragmented and their ultrastructure is changed} Is the dramatic loss of mitochondrial energy generation in PTCD1 KO cells accompanied by a change in mitochondrial number or morphology? We first estimated gross mitochondrial content of WT and PTCD1 KO cells by Western blot using antibodies against HSP60, VDAC1 and TOM20, three commonly used marker proteins for mitochondria. No difference in the abundance of these proteins was apparent in lysates from WT versus PTCD1 KO cells (Fig. $3 A, B$ ). Another method of assessing the number of mitochondria per cell uses qPCR to determine the ratio of mitochondrial versus nuclear genome copies. Quantitative real-time PCR with primers against three different regions of the mitochondrial DNA (mtDNA) and against $\beta$-2microglobulin on the nuclear genome (nDNA), revealed no difference in the ratios of mtDNA to nDNA content between WT cells and the different PTCD1 KO cell lines (Fig. 3C).

To investigate the morphology of the mitochondrial network we stained mitochondria using an antibody against TOM20 and performed confocal immunofluorescence microscopy. Overall the intensity of the TOM20 immunostaining in PTCD1 KO cells was not noticeably altered but compared with the tubular-shaped mitochondrial network in WT cells, the staining appeared granular, indicating mitochondrial fragmentation (Fig. 3D). We quantified mitochondrial morphology using the thresholding and particle mask functions in ImageJ and found the mitochondria in PTCD1 KO cells to be smaller and more circular in shape (Fig. 3E). Cells with residual expression of PTCD1 (KO\#3 ${ }^{\text {hypo }}$ ) contained mitochondria whose morphology more closely resembled the WT (Fig. 3E). There was a trend toward a higher number of mitochondria (defined as particles) in the $\mathrm{KO}$ cells, but this only reached significance in the PTCD1 KO\#1 cell line.

Disruption of OXPHOS and changes in the bioenergetic state of mitochondria have been shown to derange the structure of mitochondrial cristae (Zick et al., 2009). Therefore, we examined cristae morphology in WT and PTCD1 KO cells by transmission electron microscopy (TEM). In cells without PTCD1, mitochondria appeared enlarged (swollen) and contained fewer cristae (Fig. 3F, and 
A
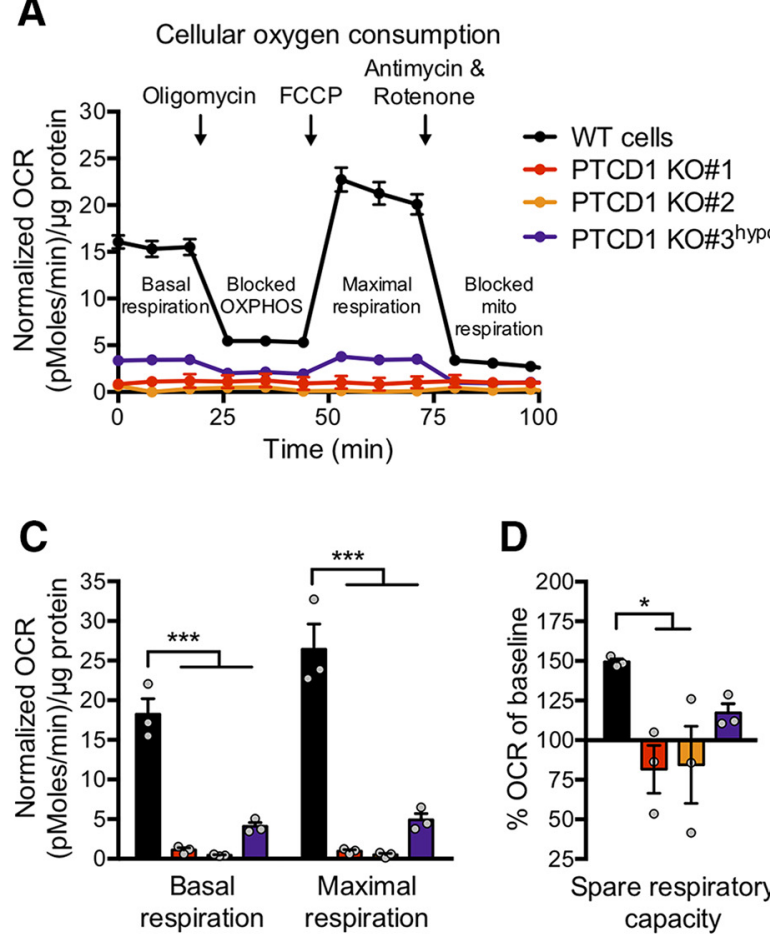

E

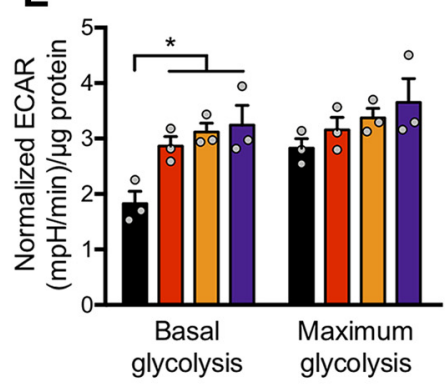

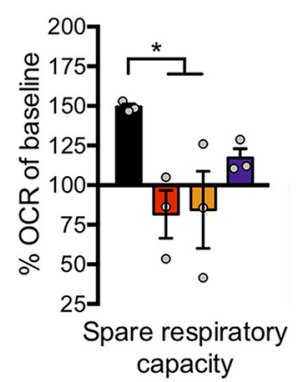

$\mathbf{F}$

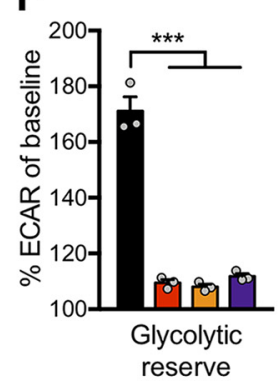

B

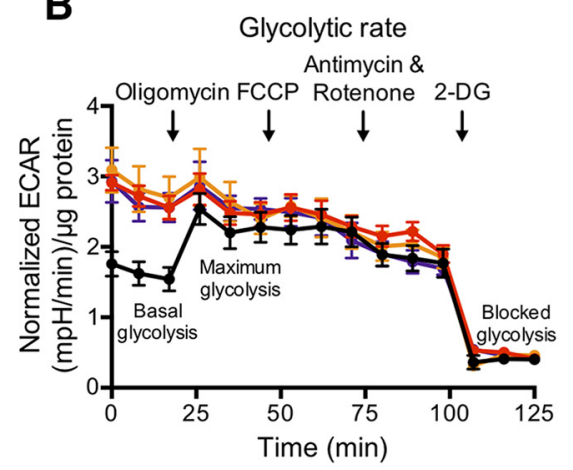

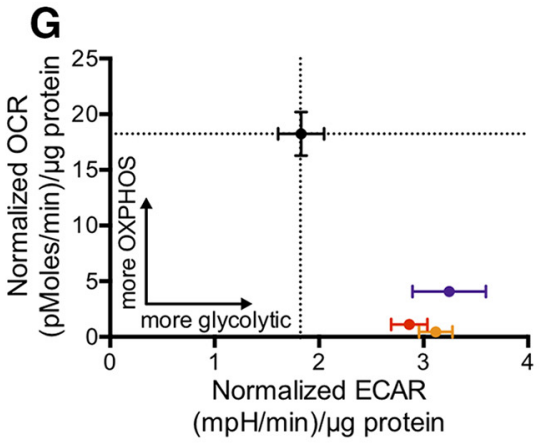

H
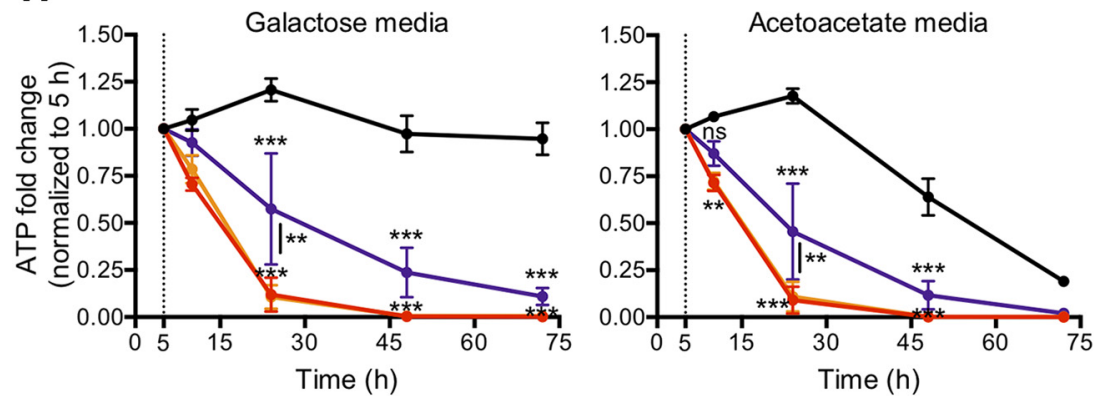

Figure 2. PTCD1 KO cells lack oxidative phosphorylation and rely on glycolysis for energy generation. $A, B$, Representative traces from Seahorse assay showing cellular $0 C R$ and ECAR (measure of glycolysis) of WT and KO (PTCD1 KO\#1,2) cells and cells with hypomorphic PTCD1 expression (PTCD1 KO\#3 hypo). Arrows signal addition of inhibitors to interrogate indicated respiratory parameters. $C, D$, Quantification of basal and maximal respiration and of the spare respiratory capacity (ability to boost OCR above baseline upon increased ATP demand) of WT and KO cells. E, F, Quantitative Seahorse data of baseline and peak (after blocking OXPHOS) glycolysis and of glycolytic reserve in cells with and without PTCD1. G, Summary of energy metabolism phenotype of PTCD1 K0 cells. Additional Seahorse assay controls are provided in Figure 2-1, available at https://doi.org/10.1523/JNEUROSCI.0116-19.2019.f2-1. H, Cellular ATP levels in WT and KO cells cultured in media with galactose or acetoacetate instead of glucose. Media was changed $(0 \mathrm{~h})$ and cells were lysed to measure ATP concentrations at indicated time points. All data for quantifications from three independent experiments and presented as mean \pm SEM. ${ }^{*} p \leq 0.05,{ }^{* *} p \leq 0.01,{ }^{* * *} p \leq 0.001$ between cell lines by one-way ANOVA $(\boldsymbol{C}-\boldsymbol{F})$ or two-way ANOVA $(\boldsymbol{H})$ with post hoc Tukey's multiple-comparison test. All OCR and ECAR values are normalized to protein content.

Fig. 3-1, available at https://doi.org/10.1523/JNEUROSCI.011619.2019.f3-1) compared with WT organelles.

Our analysis indicates that cellular mitochondrial content, as assessed by mitochondrial marker proteins and mitochondrial genome copies, is not changed in the absence of PTCD1. However, lack of PTCD1 does impact the morphology of the mitochondrial network (which appears fragmented) as well as organellar ultrastructure (swollen, with fewer cristae). 
A

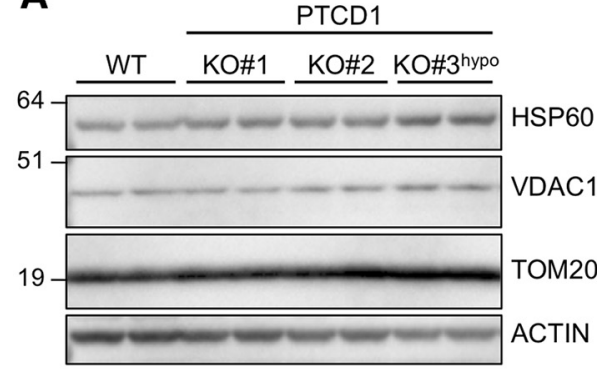

C

Mitochondrial vs. nuclear DNA content

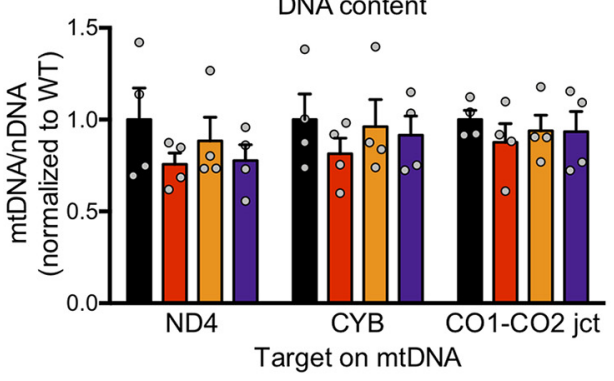

E
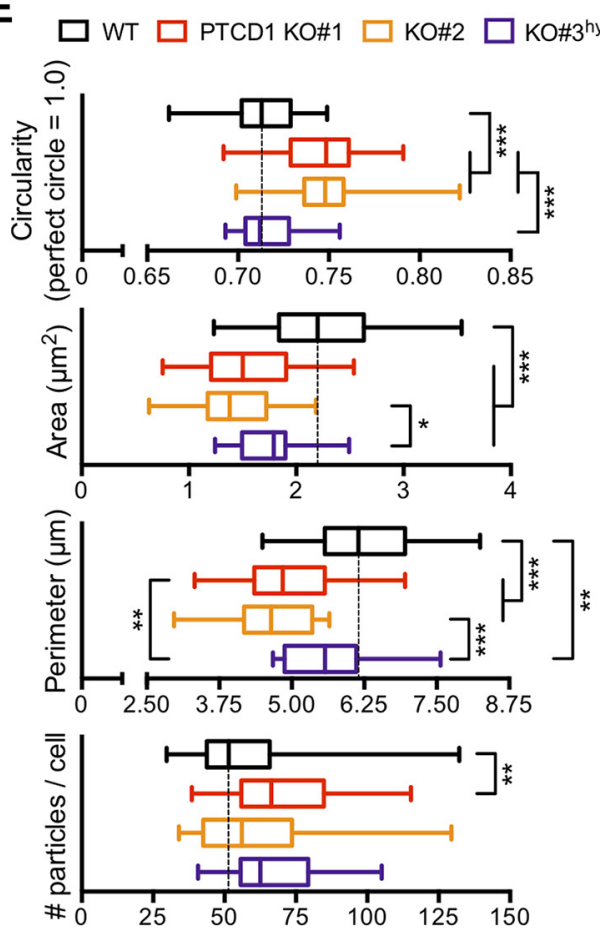

B

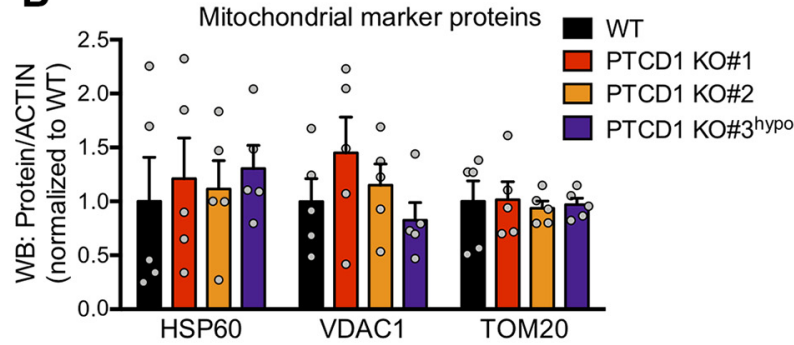

D
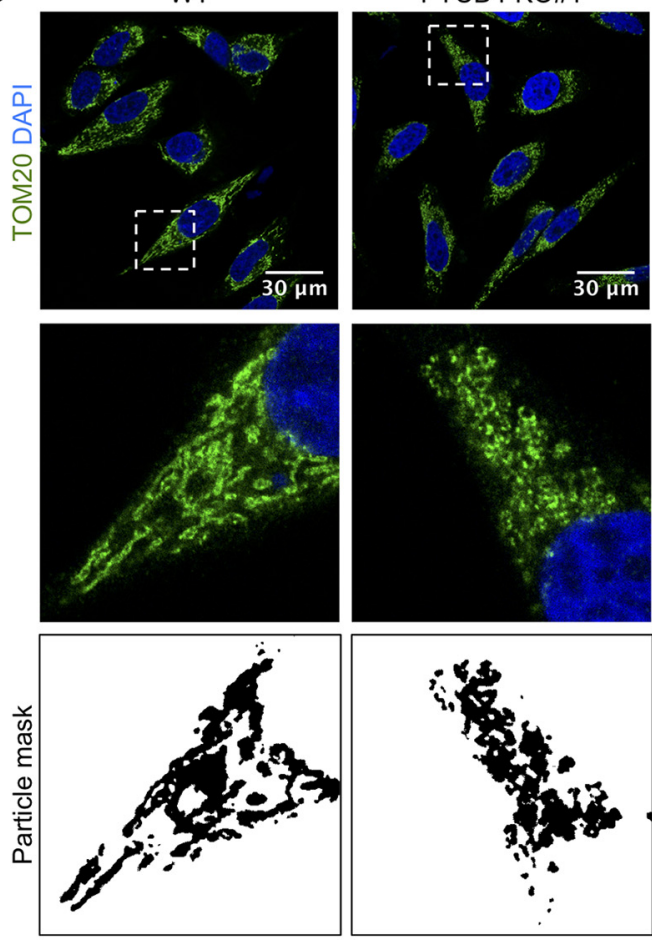

F
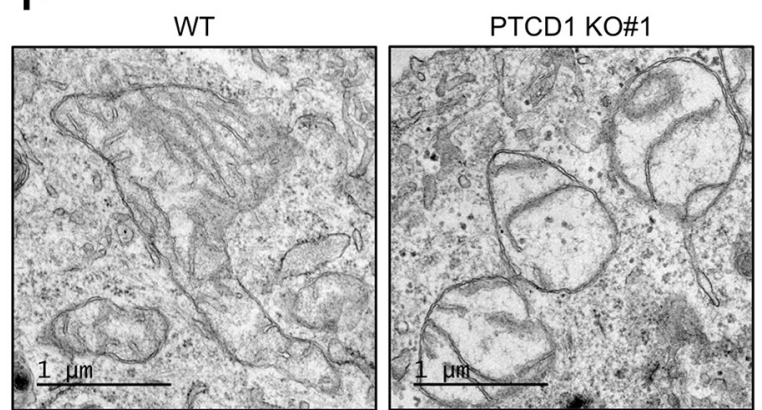

Figure 3. Mitochondria are fragmented and cristae ultrastructure is altered in the absence of PTCD1.A, Representative Western blot of mitochondrial marker proteins in the lysates of WT and PTCD1 KO cells. B, Quantification of mitochondrial marker protein abundance as shown in A. ACTIN was used as loading control and protein levels were normalized to WT cells. C, Cellular mitochondrial content was assessed by qPCR against target genes on mtDNA and nDNA genomes. Beta-2-microglobulin was used as target gene on nDNA and values were normalized to WT. $\boldsymbol{D}$, Representative confocal images show fragmented mitochondria (TOM20; green) in PTCD1 KO cells (nuclear stain: DAPI; blue). Squares indicate areas enlarged below. Bottom, Mitochondria after image processing and application of a particle mask for analysis. Scale bars, $30 \mu \mathrm{m}$. $\boldsymbol{E}$, Semiautomated particle analysis of mitochondrial morphology from confocal images as shown in $\boldsymbol{D}$. An average of 60 cells per experiment were analyzed. $\boldsymbol{F}$, Changes in mitochondrial morphology and cristae structure are apparent in representative TEM images of WT and PTCD1 K0 cells. Scale bars, $1 \mu \mathrm{M}$. Data are from five $(\boldsymbol{B})$ and four $(\boldsymbol{C}, \boldsymbol{E})$ independent experiments and presented as mean $\pm \operatorname{SEM}(\boldsymbol{B}, \boldsymbol{C})$ or box-and-whisker plots (median with $\min$ and $\max ; \boldsymbol{E}) .{ }^{*} p \leq 0.05,{ }^{* *} p \leq 0.01,{ }^{* * *} p \leq 0.001$ between cell lines by one-way ANOVA with post hoc Tukey's multiple-comparison test. Additional TEM images of WT and PTCD1 K0 cell clones are provided in Figure 3-1, https://doi.org/10.1523/ JNEUROSCI.0116-19.2019.f3-1. 


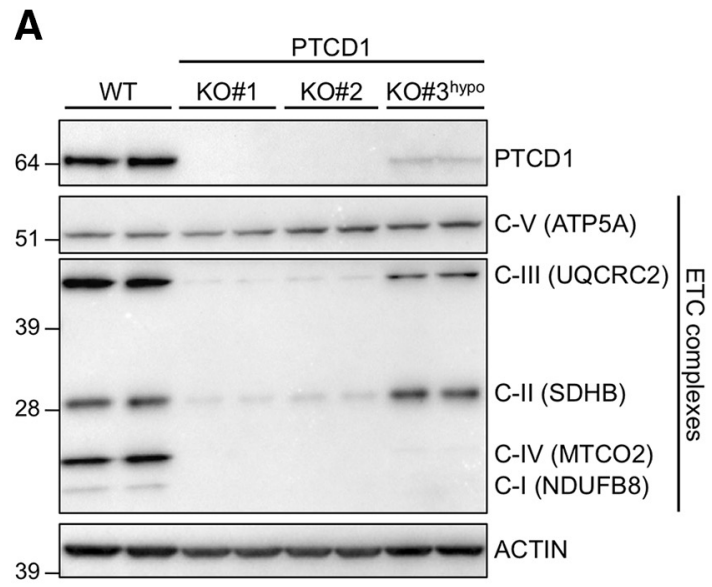

C

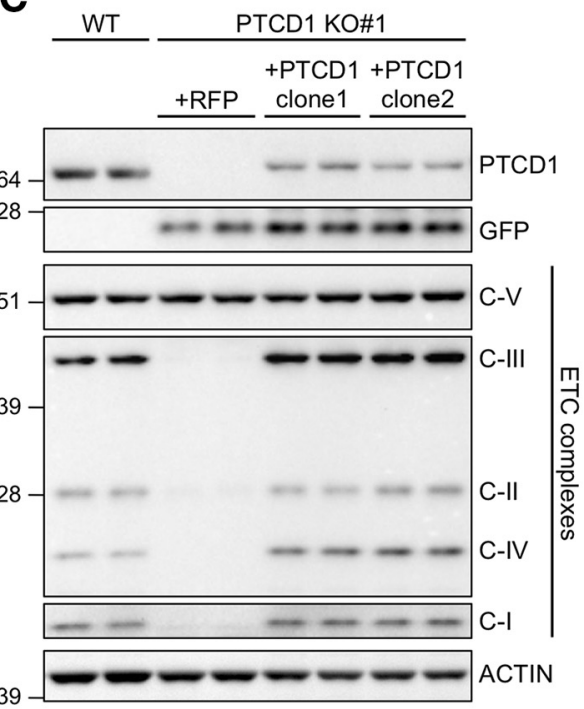

D
B
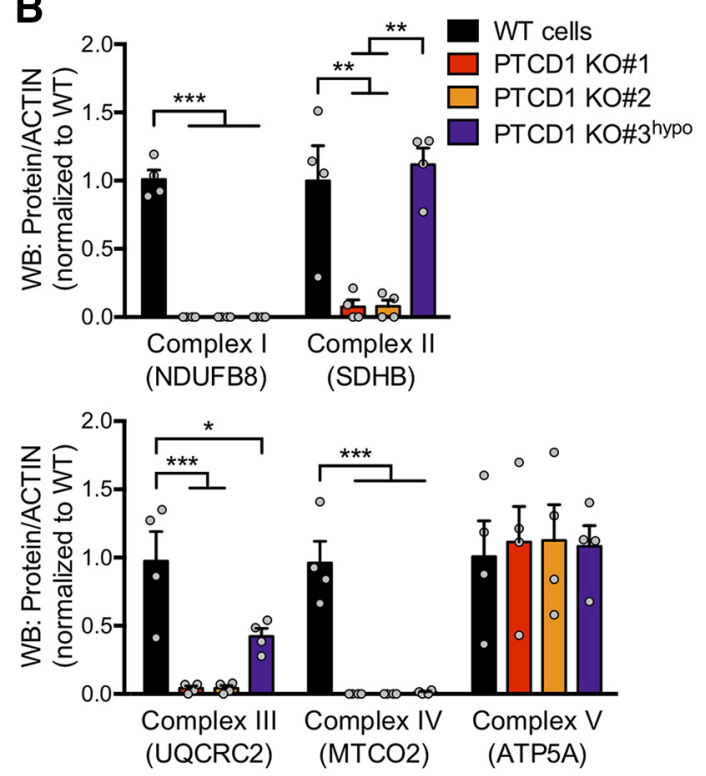

WT cells PTCD1 KO\#1 cells

E
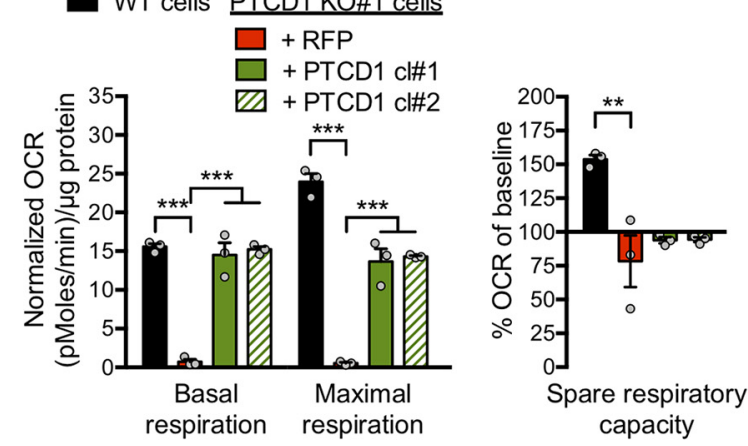

$\mathbf{F}$

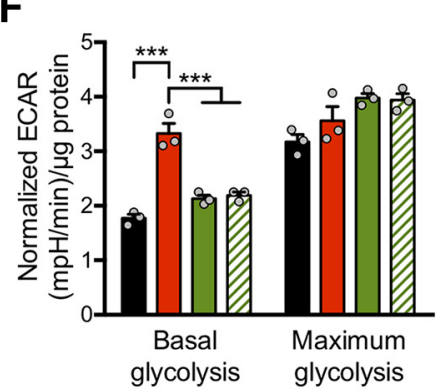

G

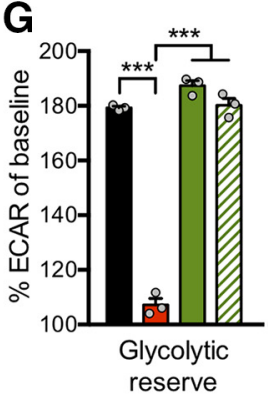

Figure 4. Lack of functional ETC complexes in PTCD1 KO cells causes deficit in oxidative phosphorylation and is reversed by PTCD1 expression. $A$, Western blot detection of PTCD1 and subunits of the electron transport chain complexes in the lysates of WT and PTCD1 K0 cells. The selected subunits are labile when unbound and are used to estimate the levels of assembled complexes. $\boldsymbol{B}$, Quantification of ETC complexes in cell lysates as shown in A. C, PTCD1 expression in K0 cells (PTCD1 KO\#1) was restored by stably expressing PTCD1-Flag (with GFP-T2A-puromycin, RFP as control) and ETC complexes in two independent rescue cell lines (KO\#1 + PTCD1 clone1, clone2) were assessed by Western blotting as in $A$. GFP detection was used to confirm equal transgene expression. Note that the Flag tag on PTCD1 slightly increases its MW. D-G, Summary of Seahorse assay experiments with WT and PTCD1 KO (KO\#1 + RFP) cells and K0 cells re-expressing PTCD1 (K0\#1 + PTCD1 clone1, clone2). $\boldsymbol{D}, \boldsymbol{E}$ Quantification of baseline, peak (ETC uncoupled), and spare (difference between basal and maximum) respiration. $\boldsymbol{F}, \mathbf{G}$, Glycolytic flux at baseline and upregulated in response to blocked mitochondrial ATP production (glycolytic reserve). Data for quantifications from four $(\boldsymbol{B})$ or three $(\boldsymbol{D}-\boldsymbol{G})$ independent experiments and presented as mean $\pm S E M .{ }^{*} p \leq 0.05,{ }^{* *} p \leq 0.01$, ${ }^{* * *} p \leq 0.001$ between cell lines $(\boldsymbol{B})$ by one-way ANOVA with post hoc Tukey's or versus KO\#1 + RFP cells $(\boldsymbol{D}-\boldsymbol{G})$ by one-way ANOVA with post hoc Dunnett's multiple-comparison test. All 0CR and ECAR values normalized to protein content.

The respiratory deficit of PTCD1 KO cells is caused by the loss of electron transport chain complexes and can be rescued by expression of PTCD1

OXPHOS depends on the assembly of five ETC complexes (C-I$\mathrm{C}-\mathrm{V})$ at the inner membrane of mitochondria. Given that PTCD1 KO cells present with a striking lack of OXPHOS, we investigated the integrity of the ETC by immunoblotting for a specific subunit of each ETC complex. No change in the abundance of ATP5A, representing complex $\mathrm{V}$, was apparent in any of the cell lines (Fig. $4 A, B)$. By contrast, representative subunits of C-II (SDHB) and C-III (UQCRC2) were barely detectable in PTCD1 KO cells, whereas MTCO2 and NDUFB8 (subunits of C-IV and C-I, re- 


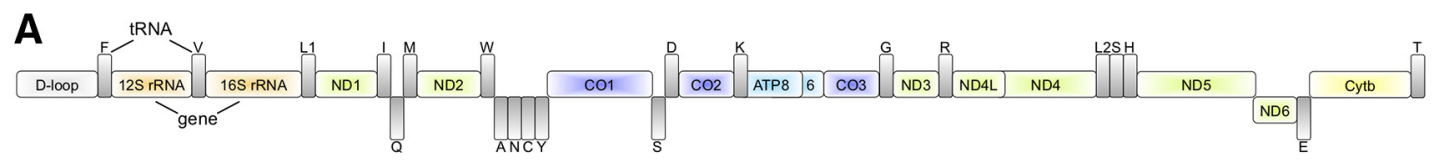

B
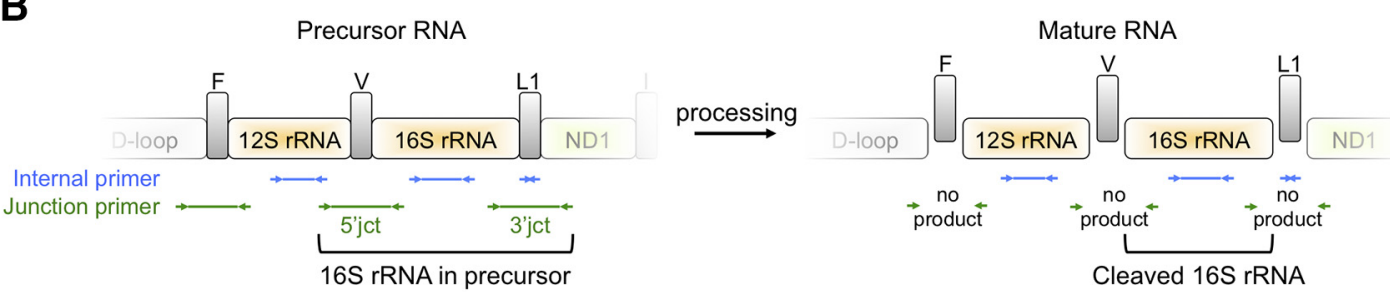

C

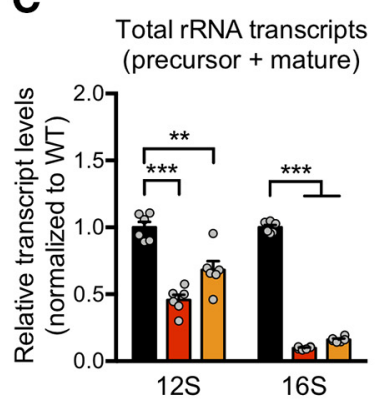

D

Precursor junction transcripts

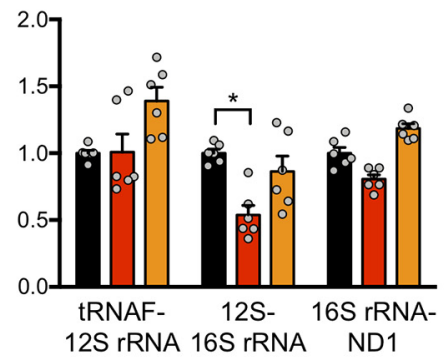

E rRNA mature/precursor transcripts

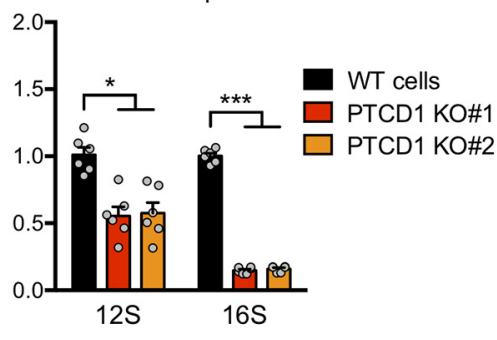

$\mathbf{F}$

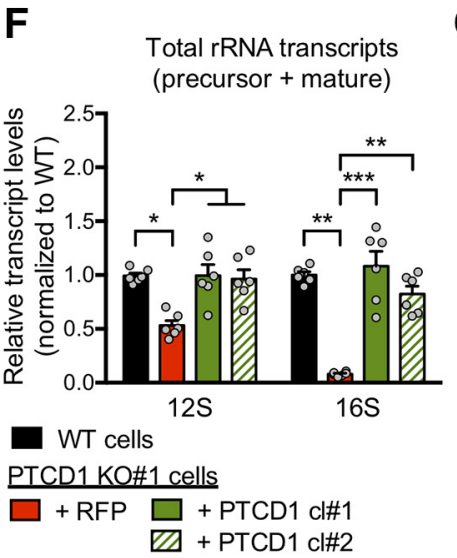

G
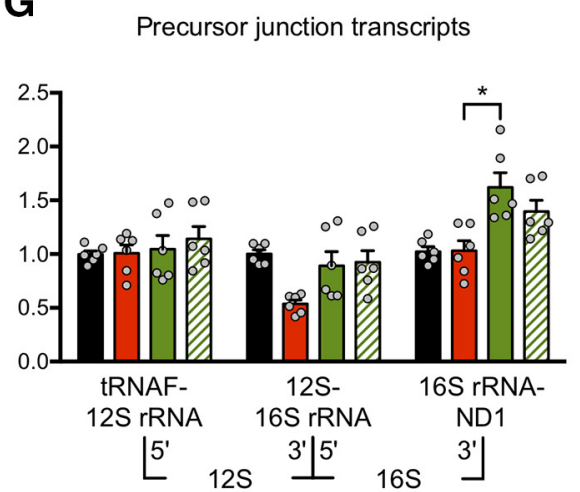

H rRNA mature/precursor transcripts

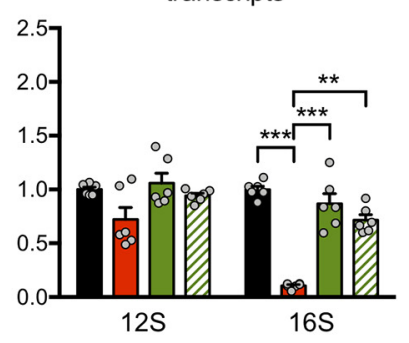

Figure 5. Mitochondrial rRNA is reduced in PTCD1 KO cells. A, Schematic representation of the mitochondrial genome in which genes (colored boxes) are interspersed by tRNAs (gray boxes). Genes on the heavy and light strands are depicted on top and bottom, respectively. $\boldsymbol{B}, 0$ verview of qPCR assay with examples of primer locations. Internal primers recognize both precursor and processed transcripts, primers that span junctions only report precursor transcripts but not processed RNA. C-E, Quantification of mitochondrial rRNA transcript levels in WT and PTCD1 K0 cells by qPCR. $C$, Mitochondrial total (precursor and mature) rRNA transcript levels. D, Relative precursor rRNA transcript abundance as measured with junction primers. $\boldsymbol{E}$, Ratios of mature to precursor $12 S$ and 165 rRNA transcripts. For quantification of the remaining mitochondrial transcripts, see Figure 5-1, https://doi.org/10.1523/JNEUROSCI.0116-19.2019.f5-1. F- $\boldsymbol{H}$, Mitochondrial rRNA transcript levels in WT, PTCD1 K0 (KO\#1 + RFP) and rescue cell lines (KO\#1 + PTCD1 clone1, clone2). Total $(\boldsymbol{F})$ and precursor $(\boldsymbol{G})$ mitochondrial rRNA transcript levels and mature/precursor ratios $(\boldsymbol{H})$ were analyzed as in $\boldsymbol{C}-\boldsymbol{E}$. Data are pooled from three independent experiments and presented as mean \pm SEM. ${ }^{*} p \leq 0.05,{ }^{* *} p \leq 0.01,{ }^{* * *} p \leq 0.001$ versus $\mathrm{KO}$ cell lines $(\boldsymbol{C}-\boldsymbol{E})$ or versus KO\#1+RFP cells $(\boldsymbol{F}-\boldsymbol{H})$ by one-way ANOVA with post hoc Dunnett's multiple-comparison test.

spectively) were completely absent. KO\#3 hypomorph cells retained normal expression of C-II, but showed lower levels of C-III and loss of C-I and C-IV subunits (Fig. 4A,B).

To confirm that the ETC and OXPHOS phenotypes of the PTCD1 KO cells are truly caused by the disruption of the PTCD1 gene, we generated stably transfected cell lines in which a PTCD1 construct (PTCD1-Flag with GFP-T2A-puromycin) was reintroduced in the PTCD1 KO\#1 background. In two independent clones expressing PTCD1 protein at levels similar to those of endogenous PTCD1 in WT cells, the expression of all ETC com- plexes was fully rescued, as assessed by Western blot (Fig. 4C). Furthermore, the basal respiration rates in the rescue cell lines were indistinguishable from WT cells (Fig. $4 D$ ), indicating that the restored ETC complexes were indeed functional. The reexpression of PTCD1 in the KO\#1 background also significantly elevated maximal respiration rate and partially rescued spare respiratory capacity, although not to normal WT levels (Fig. 4D,E). In line with restored mitochondrial ATP generation we also detected normalized glycolytic flux upon re-expression of PTCD1 in the $\mathrm{KO}$ background (Fig. 4F, G). A control stable cell line ex- 
pressing RFP instead of PTCD1 failed to rescue the ETC biochemistry and respiration deficit of PTCD1 KO cells (Fig. 4C-G).

Together these experiments demonstrate that specific loss of PTCD1 in cultured cells leads to the depletion of functional ETC complexes which in turn abolishes the cell's ability to generate ATP through mitochondrial OXPHOS.

\section{Mitochondria in PTCD1 KO cells are deficient of mature 16S ribosomal RNA}

How does the absence of PTCD1 lead to the loss of a functional ETC within mitochondria? In addition to the 13 proteins that are essential for ETC assembly and function, the mitochondrial genome encodes the $12 \mathrm{~S}$ and $16 \mathrm{~S}$ ribosomal RNA (rRNA) that are part of the small and large subunit of the mitochondrial ribosome. We interrogated the steady-state levels of mitochondrial transcripts in our PTCD1 KO cells using qPCR.

The mitochondrial genome (Fig. 5A) produces long precursor transcripts that contain the protein coding regions separated by interspersed mitochondrial tRNAs (Fig. 5B). Processing of the precursor transcript by RNaseP and RNaseZ then produces the mature mRNAs and rRNAs (Fig. 5B). Using primers that target within the specific rRNAs and protein coding regions (internal primers) we measured the total abundance of these transcripts (i.e., the sum of precursor and mature RNAs) in PTCD1 KO cells relative to WT cells. Additionally, we used primers that span the tRNA junctions (junction primers), and as such do not target mature RNAs (Fig. 5B), to specifically quantify the abundance of precursor transcripts.

We detected a dramatic drop in the total abundance (precursor and mature) of the $16 \mathrm{~S}$ transcripts, and to a lesser degree of the 12S, in both PTCD1 KO cell lines (Fig. 5C). The level of the precursor transcript containing the $16 \mathrm{~S}$ and $12 \mathrm{~S}$ rRNAs was not or only slightly changed (Fig. 5D), indicating that the mature rRNA transcripts were specifically decreased. Dividing the number of total transcripts (internal primers) by the precursor (junction primers) allows an estimation of the mature/precursor ratio; this ratio underscores the sharp drop of mature $16 \mathrm{~S}$ rRNA in the absence of PTCD1 (Fig. 5E). Confirming the link between PTCD1 and mitochondrial rRNA expression, both rescue cell lines (PTCD1 KO\#1 + PTCD1 clone1, clone2) contain total 12S and $16 \mathrm{~S}$ rRNA levels that are comparable to WT cells (Fig. 5F). PTCD1 re-expression in the KO background also normalized the ratio of $12 \mathrm{~S}$ and $16 \mathrm{~S}$ mature/precursor transcripts (Fig. $5 \mathrm{H}$ ) and, interestingly, led to a small increase of $16 \mathrm{~S}-\mathrm{ND} 1$ junction reads, the mtDNA region that has been shown to interact with PTCD1 (Rackham et al., 2009; Fig. 5G).

Measurement of the 13 transcripts coding for ETC subunits revealed considerable variability between PTCD1 KO\#1 and $\mathrm{KO} \# 2$ cell lines, but we noticed in both a trend toward elevated precursor RNA and overall (including processed) mitochondrial transcripts (Fig. 5-1A,B, available at https://doi.org/10.1523/ JNEUROSCI.0116-19.2019.f5-1). We also probed for changes in the levels of mitochondrial tRNAL1 and tRNAL2, two of the 22 tRNA species encoded by the mitochondrial genome. In line with a previous report (Rackham et al., 2009) we detected an increase in overall tRNAL1 transcript abundance upon the loss of PTCD1 expression (albeit only significant in PTCD1 KO\#2) and a shift toward more mature tRNAL1 (Fig. 5-1C, available at https:// doi.org/10.1523/JNEUROSCI.0116-19.2019.f5-1).

In summary our qPCR data show that lack of PTCD1 leads to dramatically reduced levels of mature mitochondrial 16S, and to a lesser degree $12 \mathrm{~S}$, rRNA transcripts. Because $12 \mathrm{~S}$ and $16 \mathrm{~S}$ rRNAs function as the backbone of the mitochondrial ribosome, it is conceivable that scarcity of mature rRNAs will reduce the num- ber of functional mitoribosomes and therefore impede the production of ETC subunits encoded by the mitochondrial genome.

\section{Mass spectrometry analysis reveals reduction of mitoribosomal proteins in the absence of PTCD1 and lack of ETC subunits encoded by the mitochondrial genome}

Taking an unbiased approach to identify the biochemical pathways affected by the absence of PTCD1, we used quantitative MS to compare the cellular and mitochondrial proteomes of WT and PTCD1 KO cells (Fig. 6-2, available at https://doi.org/10.1523/ JNEUROSCI.0116-19.2019.f6-2). We purified mitochondria from WT and PTCD1 KO\#1 cells and confirmed the quality of the isolate by immunoblotting for marker proteins (Fig. 6-1 A, available at https://doi.org/10.1523/JNEUROSCI.0116-19.2019.f6-1).

Label-free quantitative MS of the total cell lysate identified a total of 5075 unique proteins of which 304 (6.0\%) proteins exhibited a $\log 2$ fold-change of $>1.5$ in the PTCD1 KO compared with WT. Of those, 149 proteins (49\%) were more abundant and 155 proteins $(51 \%)$ were decreased in the total lysate of KO cells (Fig. 6A). Several of the most prominently downregulated proteins are subunits of the ETC and mitochondrial ribosome, whereas enzymes involved in the metabolism of glucose, fatty acids, and amino acids were among those increased (Fig. 6A).

To systematically identify biological processes and pathways most affected by these changes, we used the PANTHER overrepresentation analysis tool. Upregulated proteins in the PTCD1 KO cells mostly clustered into fatty acid and amino acid metabolic pathways but cell adhesion proteins were also slightly enriched (Fig. $6 B$ ). On the other hand, three processes were dramatically underrepresented in the PTCD1 KO whole-cell proteome: oxidative phosphorylation, mitochondrial translation and respiratory electron transport (Fig. 6B). In line with our finding of greatly reduced levels of mature mitochondrial $16 \mathrm{~S}$ rRNA, the protein class most reduced in the KO cells was ribosomal proteins of the mitochondrial large subunit (mtLSU); 12 of the 13 downregulated ribosomal proteins identified belong to the mtLSU. Oxidoreductases were another protein class downregulated in the absence of PTCD1 with all but two of them belonging to the ETC. We did not observe an enrichment of a specific protein class in the PTCD1 KO cells.

To better detect low abundance mitochondrial proteins, we next compared the proteomes of purified mitochondria from WT and PTCD1 KO\#1 cells. The change in abundance of ETC proteins previously measured by Western blotting (Fig. $4 A$, and Fig. 6-1 $A$, available at https://doi.org/10.1523/JNEUROSCI. 0116-19.2019.f6-1) was corroborated by the mitochondrial MS (Fig. 6-1 B, available at https://doi.org/10.1523/JNEUROSCI. 0116-19.2019.f6-1).

Does the lack of PTCD1 affect the steady-state levels of proteins involved in the transcription, replication and maintenance of the mitochondrial genome? Looking at the abundance of 30 key proteins (Fig. 6-3, available at https://doi.org/10.1523/ JNEUROSCI.0116-19.2019.f6-3) of those machineries we did not observe a general downregulation in the PTCD1 KO cells (Fig. $6 C$ ). Interestingly, however, RNZ2 (also known as RNaseZ/ ELAC2) and mitochondrial transcription termination factor 4 (MTEF4) were the two proteins in this group most reduced when comparing KO versus WT cells (Fig. 6C). This may be significant because ELAC2 has been shown to interact with PTCD1 (Sanchez et al., 2011) and is responsible for cleaving mitochondrial precursor transcripts at the $3^{\prime}$ end during maturation (Brzezniak et al., 2011; Sanchez et al., 2011). Moreover, MTEF4 binds the $16 \mathrm{~S}$ rRNA and targets the methyltransferase NSUN4 (5-methylcyto- 
A

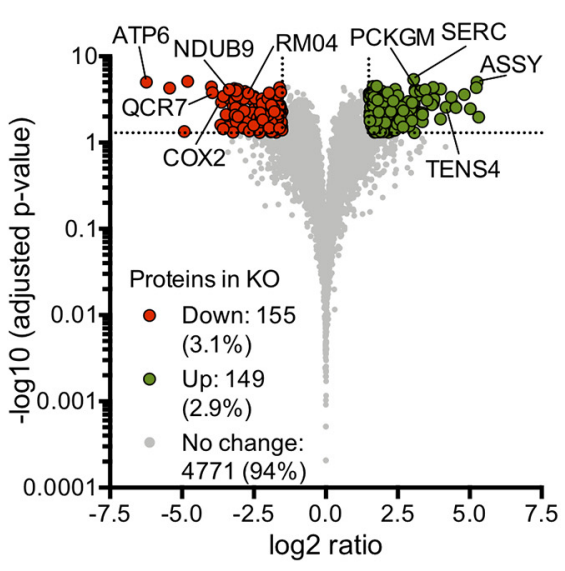

B

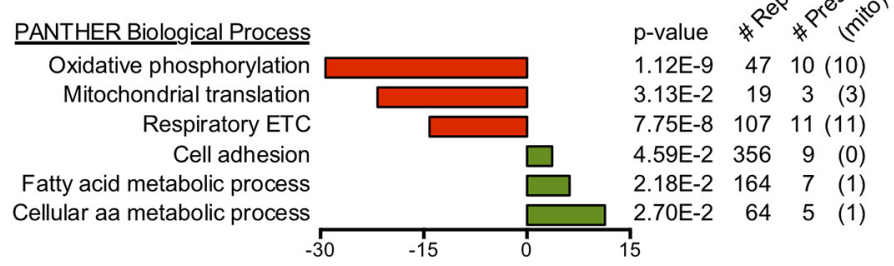

PANTHER Protein Class

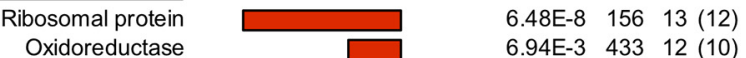

Oxidoreductase

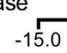

\section{C}
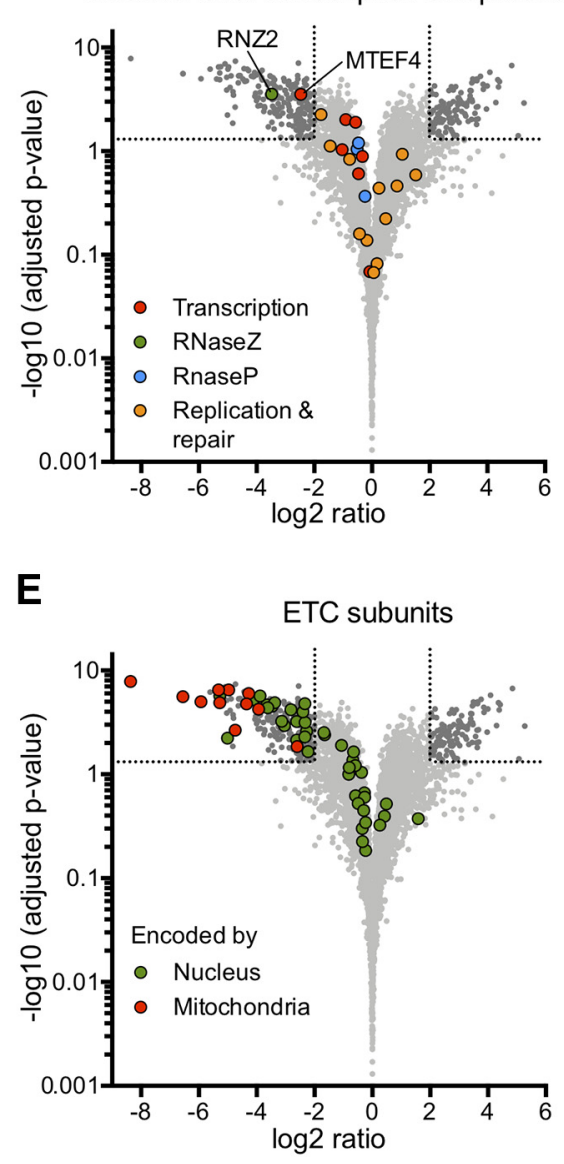

D

Mitochondrial ribosome

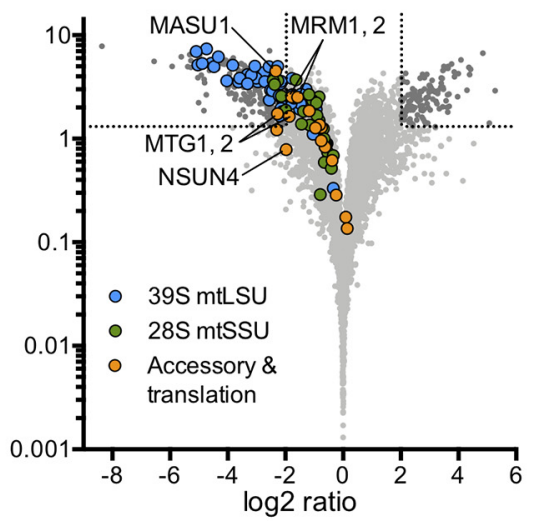

Figure 6. Mass spectrometric analysis confirms loss of mitoribosome subunits and mitochondrial translation in the absence of PTCD1. A, Volcano plot showing quantitative comparison of WT and PTCD1 KO\#1 cell proteomes. A total of 5075 unique proteins were identified in the cell lysates and the abundance of 304 was significantly different in the KO compared with WT cells. B, PANTHER overrepresentation analysis of proteins depleted or enriched in KO cell lysates. $C-E, M S$ analysis of mitochondria isolated from WT and PTCD1 KO\#1 cells. Volcano plots highlight changes in the abundance of selected proteins (each represented by colored dots) between WT and KO cells. C, Comparison of key proteins involved in mitochondrial transcription, replication, and genome maintenance. $\boldsymbol{D}$, Abundance of mitochondrial ribosomal proteins of the small $28 \mathrm{~S}$ and large 395 mitoribosome subunit and of accessory and translational factors. $\boldsymbol{E}$, Abundance of ETC core subunits in WT and KO cells. Data collected from three independent biological experiments. Significance criteria: $\log 2 \mathrm{FC}>1.5(\boldsymbol{A}, \boldsymbol{B}), \log 2 \mathrm{FC}>2.0(\boldsymbol{C}-\boldsymbol{E})$; $\boldsymbol{P}<0.05$. PANTHER analysis with Fisher's exact and FDR multiple-test correction. See Figure 6-1, available at https://doi.org/10.1523/JNEUROSCI.0116-19.2019.f6-1; Figure 6-2, available at https://doi.org/10.1523/JNEUROSCI.011619.2019.f6-2; and Figure 6-3, available at https://doi.org/10.1523/JNEUROSCI.0116-19.2019.f6-3 respectively.

sine rRNA methyltransferase) to the mitochondrial large ribosomal subunit (Cámara et al., 2011).

Further strengthening the link between PTCD1, mature 16S rRNA, and assembly of the large 39S ribosomal subunit, we found that 33 of $49 \mathrm{mtLSU}$ proteins identified were significantly reduced or completely absent in the PTCD1 KO cells (Fig. 6D). By contrast, only five of $29 \mathrm{mtSSU}$ proteins identified were significantly depleted in the PTCD1 KO proteome. Thus loss of PTCD1, 
presumably through its effect on the 16S rRNA, has its biggest impact on the assembly of the large 39S ribosomal subunit.

In the category of ribosomal accessory proteins and proteins involved in mitochondrial translation (Fig. 6-3, available at https://doi.org/10.1523/JNEUROSCI.0116-19.2019.f6-3), only MASU1 (mitochondrial assembly of ribosomal large subunit protein 1) and MTG1 (mitochondrial ribosome-associated GTPase 1) were significantly reduced in the KO (Fig. 6D). MRM1 (mitochondrial rRNA methyltransferase 1) and MRM2 as well as NSUN4 and MTG2, all of which are required for proper 16S rRNA maturation and mtLSU assembly (Cámara et al., 2011; Kotani et al., 2013; Rorbach et al., 2014) were also reduced but did not quite reach statistical significance.

Deficits in rRNA maturation and subsequent mitoribosome assembly will eventually lead to the shutdown of mitochondrial translation. This should be evident in PTCD1 KO cells by the absence of ETC subunits encoded by the mitochondrial genome and translated at the mitoribosome. In our MS analysis of WT mitochondria, we were able to detect 52 of the 67 ETC core subunits annotated by the HUGO Gene Nomenclature Committee (Fig. 6-3, available at https://doi.org/10.1523/JNEUROSCI.011619.2019.f6-3). Of the 54 ETC subunits encoded by nuclear genes we identified 41, with 19 being significantly reduced and the remaining not significantly changed between WT and KO cells (Fig. $6 E)$. We also observed 11 of the 13 ETC subunits encoded by the mitochondrial genome in WT cells. However, we failed to detect any peptides for these subunits in PTCD1 KO cells, indicating the complete absence of mitochondrially encoded ETC subunits and placing them among the most dramatically changed proteins in the entire dataset (Fig. 6E, and Fig. 6-1C, available at https:// doi.org/10.1523/JNEUROSCI.0116-19.2019.f6-1).

Our MS data confirm a lack of functional ETC complexes in PTCD1 KO cells. Although the levels of many ETC subunits contributed by the nucleus and imported into the mitochondria are only slightly lower or unchanged, subunits translated by the mitoribosome are absent.

We did not find a dramatic impact on mitochondrial replication and transcription, but the majority of mtLSU proteins are depleted in the absence of PTCD1. Together with the lack of the $16 \mathrm{~S}$ rRNA backbone, this points to defective mitoribosome assembly because of mtLSU shortage as the root cause for the observed ETC and OXPHOS phenotypes.

\section{PTCD1 KO cells rescued by R113W PTCD1 have no overt phenotype but remain dependent on glycolysis}

How does the $\mathrm{AD}$-associated $\mathrm{R} 113 \mathrm{~W}$ variant impact the function of PTCD1? We addressed this question by comparing stable cell lines that express in the PTCD1 KO background either WT PTCD1 (KO\#1 + PTCD1 WT clone1, clone2) or the R113W variant (KO\#1 +PTCD1 R113W clone1, clone2). By Western blotting, these selected rescue cell lines expressed PTCD1 at approximately equal levels and comparable to endogenous PTCD1 in WT HeLa cells (Fig. 7A, and Fig. 7-1, available at https://doi.org/ 10.1523/JNEUROSCI.0116-19.2019.f7-1). Both the WT and the R113W variant of PTCD1 were able to rescue expression of the subunits representing the ETC complexes I-IV, even to levels above WT HeLa cells (Fig. 7A,B). This was particularly pronounced for complexes I and IV in the case of WT PTCD1 rescue. Although WT PTCD1 tended to induce higher levels of complex IV subunits than the R113W variant, overall we did not observe a significant difference regarding ETC complex levels between WT and R113W PTCD1 rescue cell lines. In line with that, both WT and R113W PTCD1 increased the ratio of processed/precursor mitochondrial $12 \mathrm{~S}$ and $16 \mathrm{~S}$ rRNA to similar extents (Fig. 7C). In terms of OXPHOS and glycolytic flux, both WT and R113W rescue cell lines had very similar oxygen consumption rates. Notably, however, both cell clones expressing R113W PTCD1 exhibited a significantly higher mean glycolytic flux at baseline (Fig. $7 D$ ). This could be indicative of an increased reliance on glycolysis for energy generation in PTCD1 R113W-expressing cells. Higher baseline glycolysis rate should decrease the cell's glycolytic reserve and indeed, PTCD1 R113W rescue cell lines were unable to upregulate glycolysis in response to OXPHOS inhibition (by oligomycin) to the extent of cells rescued with WT PTCD1 (Fig. 7E).

To further explore the differential dependency of PTCD1 WT and R113W cells on glycolysis, we compared ATP generation over time in the presence of glucose or galactose in the culture media. With glucose as abundant source of energy, cultures of both PTCD1 WT and R113W rescue cell lines produced similar amounts of ATP (Fig. $7 F$ ). By contrast, when switched to galactose containing media, which forces cells to shift from glycolysis to OXPHOS for energy generation, PTCD1 R113Wexpressing cells were unable to sustain ATP levels. At the $72 \mathrm{~h}$ time point, when ATP levels remained unchanged in normal cells and in PTCD1 KO cells rescued with WT PTCD1, ATP levels in the $\mathrm{R} 113 \mathrm{~W}$ rescue cells had dropped to $<50 \%$ (clone 1 ) or $<10 \%$ (clone2) of the initial ATP concentration.

Together these results reveal no overt impact of the R113W variant on baseline PTCD1 function as it relates to mitochondrial rRNA maturation and OXPHOS, and only a subtle effect on basal glycolysis. However, cells expressing the $\mathrm{AD}$-associated variant of PTCD1 show an obvious phenotype of failure to sustain ATP generation under conditions of metabolic stress, suggestive that $\mathrm{R} 113 \mathrm{~W}$ is a mild loss-of-function variant.

\section{Reducing PTCD1 expression in neurons impacts mitochondrial rRNA, energy metabolism and decreases ATP content and spontaneous activity}

We investigated the functional consequences of reduced PTCD1 activity in primary neurons using RNAi-mediated gene knockdown. Incubation with siRNA against PTCD1 (delivered in lipid nanoparticles) effectively suppressed expression of endogenous PTCD1 in cultured neurons by $68-85 \%$ over the course of $4-8 \mathrm{~d}$ (Fig. $8 A, B$ ). Despite prolonged PTCD1 reduction we did not observe cellular toxicity as assessed by live/dead cell staining with a cell membrane impermeable DNA dye after $8 \mathrm{~d}$ of siRNA treatment (Fig. 8C). Next, we checked whether a reduction of selected ETC proteins, a phenotype of PTCD1 KO HeLa cells, was also evident in neurons with decreased PTCD1 expression. Western blot analysis revealed unaltered levels of representative ETC proteins after PTCD1 knockdown (Fig. 8D, and Fig. 8-1 A, available at https://doi.org/10.1523/JNEUROSCI.0116-19.2019.f8-1) and no change in levels of mitochondrial marker proteins (Fig. 8-1 B, C, available at https://doi.org/10.1523/JNEUROSCI.011619.2019.f8-1).

Based on our previous findings, a reduction of ETC subunit abundance is likely a secondary consequence of the loss of PTCD1, downstream of its effect on rRNA processing. As such ETC protein levels may not be a sensitive readout for subtle alterations in mitochondrial and cellular energy metabolism caused by short term partial reduction of PTCD1. Therefore, we measured by qPCR mitochondrial rRNA transcript levels in neurons after PTCD1 knockdown. In line with our results from $\mathrm{KO}$ HeLa cells, the abundance of total 16S rRNA transcripts (precur- 
A

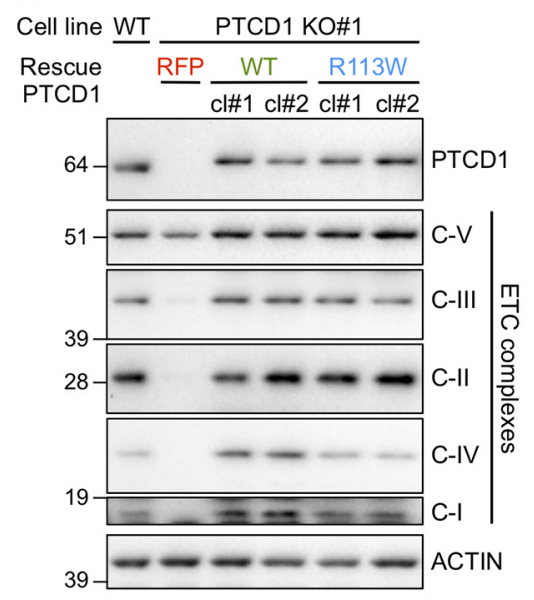

B

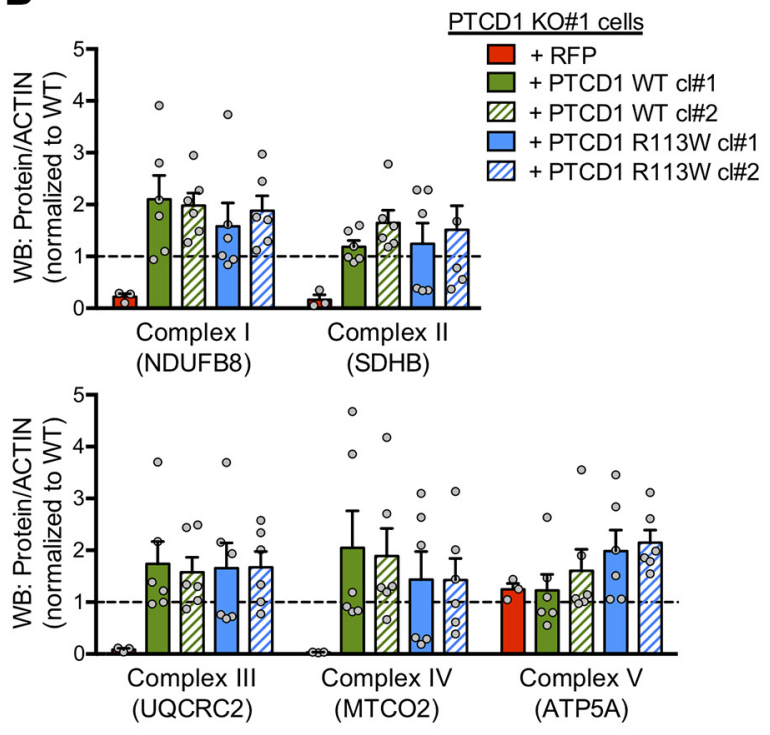

D

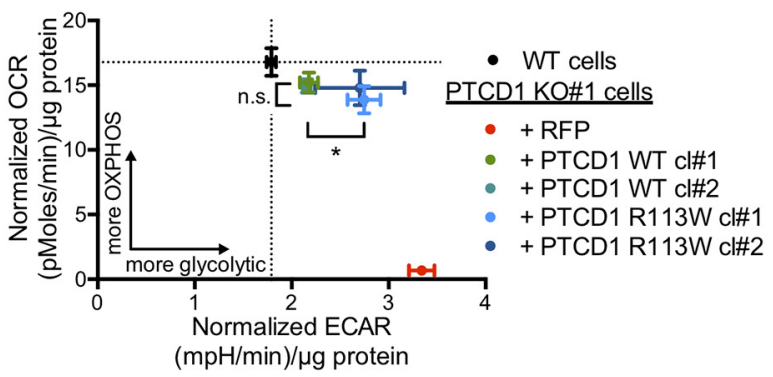

E

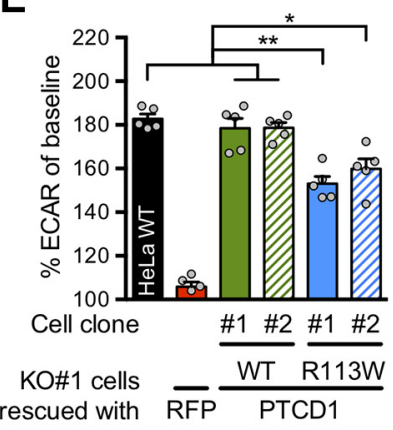

$\mathbf{F}$
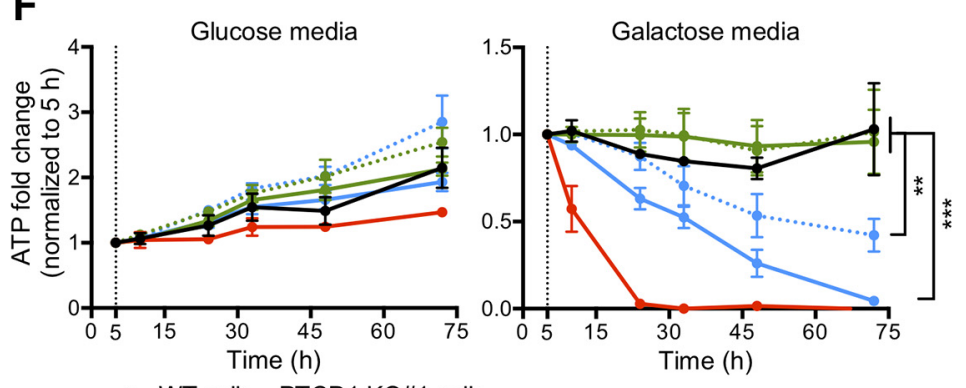

$\rightarrow$ WT cells PTCD1 KO\#1 cells

$\rightarrow+$ RFP

$\sim+$ PTCD1 WT cl\#1 $\sim$ + PTCD1 R113W cl\#1

.. + PTCD1 WT cl\#2 ... + PTCD1 R113W cl\#2

Figure 7. Rescue of PTCD1 K0 cell phenotype by WT and R113W PTCD1. A, PTCD1 expression in K0 cells (PTCD1 KO\#1) was restored by stably expressing WT or R113W PTCD1-Flag (RFP as control). Protein levels of PTCD1 and ETC subunits were determined by Western blot in the lysates of two independent rescue clones (KO\#1 + WT clone1, 2 and + R113W clone1, 2). Note that the Flag tag on PTCD1 slightly increases its MW. ACTIN was used as loading control. For quantification of PTCD1 protein levels, see Figure 7-1, available at https://doi.org/10.1523/JNEUROSCI.0116-19.2019.f7-1. $\boldsymbol{B}-\boldsymbol{F}$, The extent of rescue of different K0 phenotypes was compared between KO\#1 + PTCD1 WT and + PTCD1 R113W cell lines. WT HeLa cells and PTCD1 K0 cells (KO\#1 + RFP) are shown as controls. B, Quantification of ETC complex proteins in rescue cell lines as shown in $A$. Values were normalized to levels in WT HeLa cells. C, Comparison of 12S and 16S rRNA mature/precursor transcript ratios in cells rescued with PTCD1 WT or R113W. Values normalized to WT HeLa cells. D, OXPHOS activity and glycolytic flux in indicated cell lines as measured with the Seahorse assay platform. 0 CR and ECAR values were normalized to protein content. $\boldsymbol{E}$, Glycolytic reserve, i.e., maximal upregulation of glycolysis over baseline in response to blocked mitochondrial ATP production. $F$, Cellular ATP levels in cells cultured in media with glucose or galactose. Media was changed $(0 \mathrm{~h})$ and cells were lysed to measure ATP concentrations at indicated time points. Data pooled from four independent experiments and presented as mean \pm SEM (RFP samples shown as control). ${ }^{*} p \leq 0.05,{ }^{* *} p \leq 0.01,{ }^{* * *} p \leq 0.001$ between rescue cell lines by one-way $(\boldsymbol{B}-\boldsymbol{E})$ or two-way $(\boldsymbol{F})$ ANOVA with post hoc Tukey's multiple-comparison test.

sor and processed) was reduced after $8 \mathrm{~d}$ of siRNA-mediated PTCD1 knockdown (Fig. 8E). The amount of corresponding precursor transcripts was markedly elevated, obvious even by $4 \mathrm{~d}$ of PTCD1 knockdown (Fig. 8F). Accordingly, there was the same sharp drop in the $16 \mathrm{~S}$ rRNA mature-to-precursor ratio upon
PTCD1 knockdown that we previously observed in the PTCD1 KO cell lines (Figs. 8G, 5E). 12S rRNA transcript abundance showed a similar change, albeit to a smaller extent, and no significant reduction in overall $12 \mathrm{~S}$ rRNA levels was evident (Fig. 8E). 


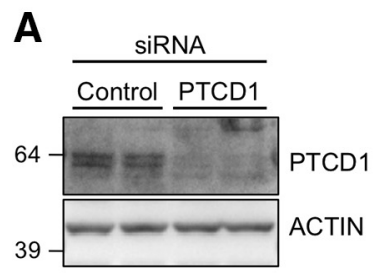

$\mathbf{E}$ Total rRNA transcripts (precursor + mature)

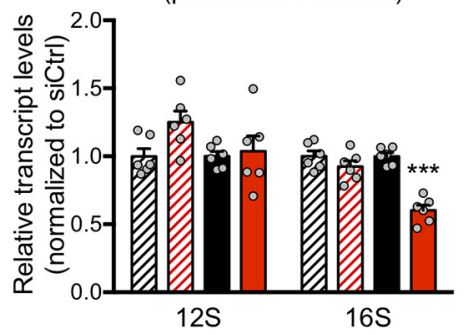

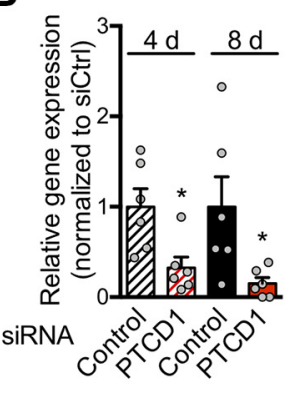

C

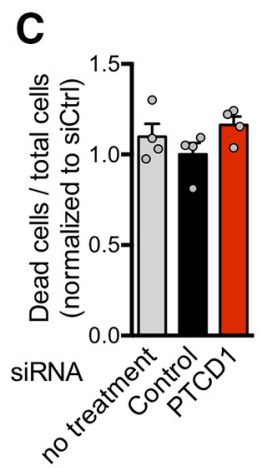

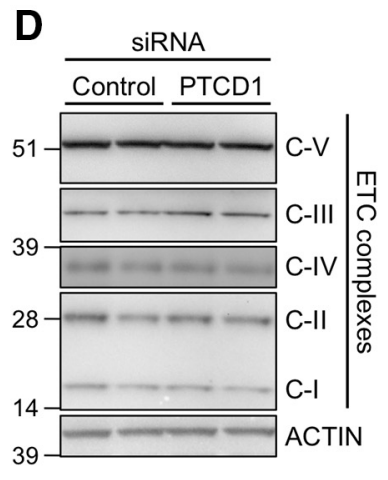

F Precursor junction transcripts $\mathbf{G}$

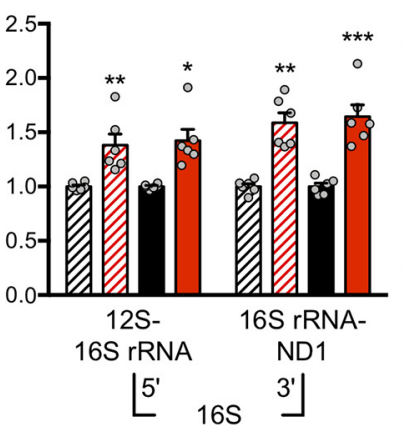

rRNA mature/precursor transcripts
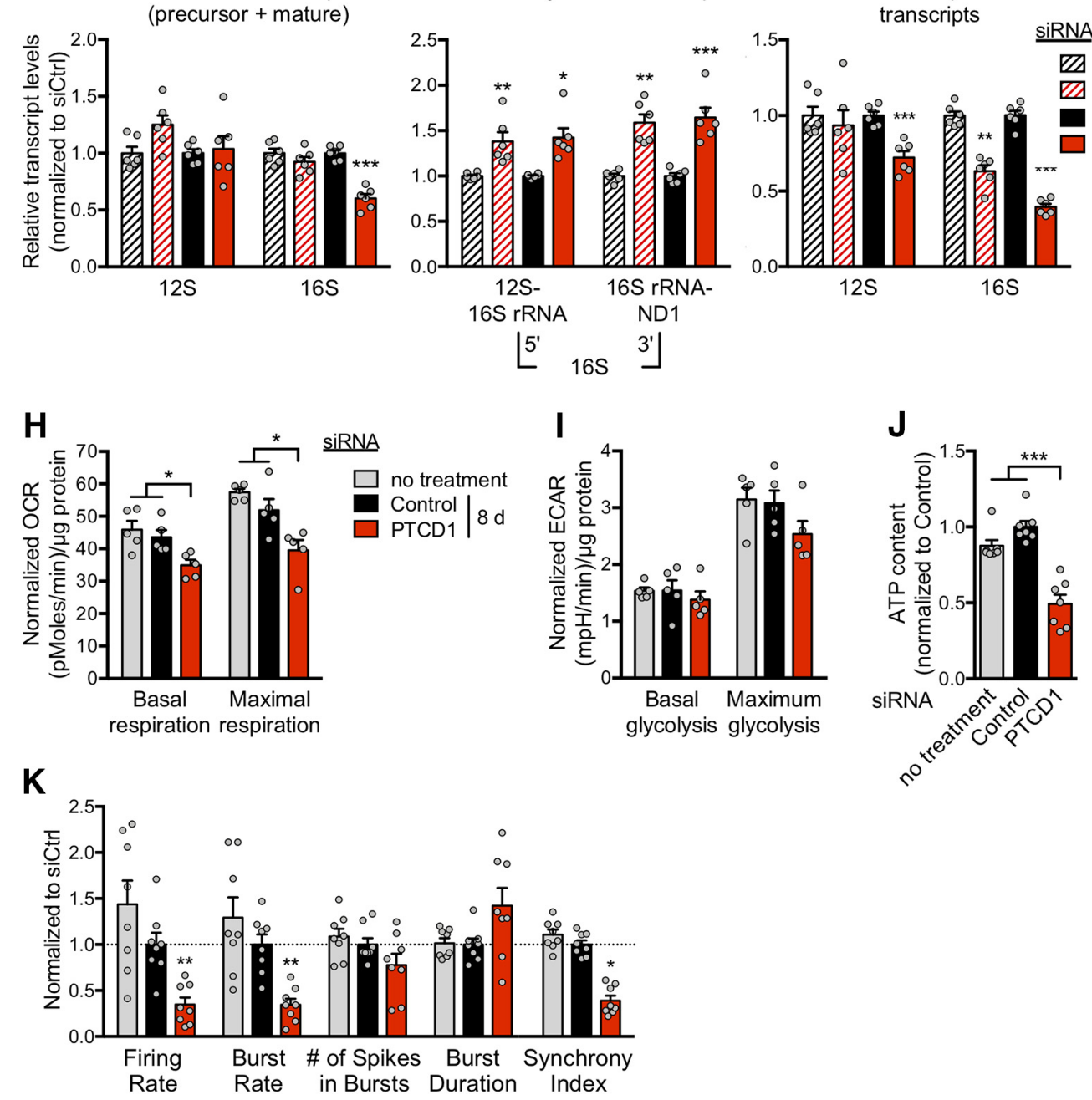

Figure 8. Neurons with reduced PTCD1 activity contain less processed mitochondrial rRNA, have lower ATP levels and diminished spontaneous activity. $\boldsymbol{A}, \boldsymbol{B}$, Confirmation of RNAi-mediated knockdown of PTCD1 in primary neurons. Neuronal cultures were incubated for 4 and $8 \mathrm{~d}$ with siRNA packaged into nanoparticles. PTCD1 protein and mRNA levels were assessed in cell lysates by Western blotting $(\boldsymbol{A})$ and $\mathrm{PPCR}(\boldsymbol{B})$. C, Imaging based quantification of cell viability after $8 \mathrm{~d}$ of PTCD1 knockdown using a fluorescent cell-impermeable dye. $\boldsymbol{D}$, Representative Western blot of ETC proteins in lysates of neurons treated with control and PTCD1 siRNA. ACTIN was used as loading control. E-G, Quantification of mitochondrial $12 S$ and 165 rRNA transcripts by qPCR in neurons after 4 and $8 \mathrm{~d}$ of siRNA treatment. $\boldsymbol{E}$, Mitochondrial total (precursor and mature) rRNA transcript levels. $\boldsymbol{F}$, Relative precursor rRNA transcript abundance determined with junction primers. $G$, Ratios of mature to precursor 125 and 165 rRNA transcripts. $\boldsymbol{H}, \boldsymbol{I}$, Quantification of OXPHOS activity $(\boldsymbol{H})$ and glycolytic flux $(\boldsymbol{I})$ in neurons with and without PTCD1 knockdown using the Seahorse assay system. Maximal respiration and glycolysis were measured after ETC uncoupling and complex V inhibition, respectively. $J$, Cellular ATP content of untreated neuron cultures and of cultures treated with the indicated siRNAs for $8 \mathrm{~d}$. $\boldsymbol{K}$, Spontaneous neuronal activity was measured with a MEA in control and PTCD1 knockdown cultures. Quantification of electrophysiological parameters is shown. Data for quantifications pooled from three independent experiments and presented as mean \pm SEM. ${ }^{*} p \leq 0.05,{ }^{* *} p \leq 0.01,{ }^{* * *} p \leq 0.001$ versus respective control by unpaired, two-tailed $t$ test $(\boldsymbol{B}, \boldsymbol{E}-\boldsymbol{G})$ and PTCD1 knockdown versus control and no treatment group by one-way ANOVA with post hoc Tukey's multiple-comparison test $(\boldsymbol{C}, \boldsymbol{H}-\boldsymbol{K})$. Additional data and quantifications of the $4 \mathrm{~d}$ time point available in Figure $8-1$, available at https://doi.org/10.1523/JNEUROSCI.0116-19.2019.f8-1. 
A lack of mature mitochondrial 16S rRNA over time should impact mitochondrial translation and eventually impair ETC function and OXPHOS. In line with that we measured lower basal and maximal oxygen consumption rates in neurons after $8 \mathrm{~d}$ of PTCD1 knockdown (Fig. $8 H$ ). There was no compensatory upregulation of glycolysis (Fig. 8I), which together points toward a reduction in ATP production in neurons as a consequence of diminished PTCD1 activity. This was confirmed when we assessed ATP concentrations in control and knockdown cultures: neurons showed only $\sim 50 \%$ of normal ATP levels after $8 \mathrm{~d}$ of PTCD1 knockdown compared with control siRNA or untreated cells (Fig. $8 J$ ).

Upkeep of the membrane potential is essential for neuronal activity and requires much energy which is thought to be generated in neurons predominantly through OXPHOS (Bélanger et al., 2011). Therefore, we asked whether the reduced OXPHOS and ATP levels caused by PTCD1 knockdown would impact the ability of neurons to fire action potentials. We used a MEA assay system to record spontaneous electrical activity in cultures of dissociated neurons with and without PTCD1 knockdown (Fig. $8 K)$. Spontaneous action potentials and strings of action potentials at high-frequency (bursts) were significantly less frequent upon PTCD1 knockdown. Once initiated, however, there were no differences in the number of spikes per burst or in burst duration. In light of our findings above this suggests that neurons with low PTCD1 levels have less energy at their disposal and therefore fire fewer action potential bursts. We also observed a reduction in synchronized periodic bursting (network activity) in cultures treated with PTCD1 siRNA. Interestingly, alterations in the electrophysiological behavior were evident only after $8 \mathrm{~d}$ of PTCD1 knockdown but not after $4 \mathrm{~d}$ (Fig. 8-1D, available at https:// doi.org/10.1523/JNEUROSCI.0116-19.2019.f8-1). Changes in the production and secretion of the $\mathrm{A} \beta$ peptide, which is believed to be a key pathogenic agent in $\mathrm{AD}$, have been linked to altered neuronal activity (Kamenetz et al., 2003), however, we observed no difference in $A \beta$ levels in the culture medium of neurons with or without PTCD1 knockdown (Fig. 8-1E, available at https:// doi.org/10.1523/JNEUROSCI.0116-19.2019.f8-1).

\section{Discussion}

LOAD is increasingly regarded as a complex and multifactorial disease (De Strooper and Karran, 2016; Scheltens et al., 2016). Metabolic dysfunction is clearly an early feature of $\mathrm{AD}$ pathophysiology, although causality and molecular details remain to be elucidated (Lin and Beal, 2006; Mosconi et al., 2008, 2010; Sperling et al., 2011; Zilberter and Zilberter, 2017). Although human genetics have directly implicated mitochondrial dysfunction in other neurodegenerative diseases (e.g., mutations in PINK1 and PARK2 in Parkinson's disease; mutations in subunits of C-I in Leigh syndrome) coding mutations in genes that directly impact mitochondria (e.g., mitochondrial proteins) have so far not been linked to increased $\mathrm{AD}$ risk. Because mitochondrial mutations might have large impact on organism health, perhaps it is not surprising that no common variants have been picked up in genome-wide association studies of LOAD.

In the present study we provide human genetic evidence that rare missense variants in the gene that encodes the mitochondrial protein PTCD1 might contribute to AD risk. Specifically, the rare $\mathrm{R} 113 \mathrm{~W}$ variant is consistently more frequent in $\mathrm{AD}$ patients compared with controls in multiple cohorts, suggesting a detrimental effect of this variant in terms of $\mathrm{AD}$ dementia risk. However, because of limited numbers of AD cases and controls in our exome sequencing data and the low frequency of PTCD1 variants, the association of the PTCD1 gene with AD does not reach formal genome-wide significance. Further studies using larger datasets will be required to unambiguously demonstrate the link between PTCD1 variants and AD.

Our investigation into the function of PTCD1 revealed that: (1) PTCD1 is required in cells for proper assembly of the mitochondrial ribosome, and specifically that maturation of $16 \mathrm{~S}$ rRNA (backbone of the mtLSU) depends on PTCD1. (2) OXPHOS activity is almost entirely lost in PTCD1 null cells, which become dependent on glycolysis for ATP generation. (3) Prolonged reduction of PTCD1 in primary neuronal cells lowers cellular ATP levels and impairs electrical activity. (4) The AD risk variant R113W does not abolish PTCD1 function but cells expressing only this variant show a more glycolytic pattern of metabolism compared with cells expressing WT PTCD1.

Our observation (1) is in line with a recent molecular study of PTCD1 (Perks et al., 2018), which reported that through binding to 16S rRNA and association with FASTKD2 and RPUSD4, PTCD1 facilitates pseudouridinylation and thereby stability of $16 \mathrm{~S}$ rRNA. Underlining its crucial role in mitoribosome assembly, we find mitoribosome biogenesis disrupted at several stages in the absence of PTCD1. First, the endonuclease ELAC2, which interacts with PTCD1 and liberates the 16S rRNA from the long precursor transcript (Brzezniak et al., 2011; Sanchez et al., 2011), is less abundant in PTCD1 KO cells. Second, several factors required for post-transcriptional 16S rRNA modification (MTEF4, NSUN4, MRM1, 2; Cámara et al., 2011; Rorbach et al., 2014) and mtLSU maturation (MASU1, MTG1, 2; Barrientos et al., 2003; Wanschers et al., 2012; Fung et al., 2013; Kotani et al., 2013; Brown et al., 2017) are severely reduced in PTCD1-lacking cells. The lack of functional mitoribosomes impairs mitochondrial translation and synthesis of the 13 crucial ETC subunits encoded by the mitochondrial genome. As a consequence, and even though many of the imported ETC proteins are still present in the absence of PTCD1, there is a decline in functional ETC complexes and shutdown of OXPHOS activity within mitochondria.

HeLa cells are able to entirely switch to glycolysis to compensate for a loss of OXPHOS (Marroquin et al., 2007) and therefore tolerate PTCD1 KO. Their lack of dependency on mitochondrial respiration is a possible reason why the absence of PTCD1 in HeLa cells did not lead to the strong compensatory transcriptional upregulation of $12 \mathrm{~S}$ and $16 \mathrm{~S}$ precursor RNA observed here in primary neurons and previously reported in heart and skeletal muscle (Perks et al., 2018).

Neurons have high energy requirements but use glycolysis much less than other cell types in the brain (Bélanger et al., 2011). Therefore, neurons rely heavily on mitochondrial function and OXPHOS to provide ATP for ion homeostasis and synaptic transmission and thus are especially vulnerable to mitochondrial damage (Bélanger et al., 2011; Devine and Kittler, 2018). Both A $\beta$ and hyperphosphorylated tau can damage mitochondria during AD pathogenesis (Lustbader et al., 2004; Caspersen et al., 2005; David et al., 2005; Devi et al., 2006; Rhein et al., 2009; Pérez et al., 2018), leading to impaired ETC activity, increased ROS generation and decreased ATP levels, all of which are observed frequently in brains of AD patients (Sultana et al., 2010; Mosconi et al., 2011; Cadonic et al., 2016; Joshi and Mochly-Rosen, 2018). Our results from primary neurons suggest that impaired PTCD1 function (such as resulting from a PTCD1 variant) could contribute to, or exacerbate, OXPHOS dysfunction in AD pathogenesis.

PTCD1 is expressed widely in many cell types (Rackham et al., 2009; Zhang et al., 2014), so non-neuronal cells such as astrocytes and microglia, although not studied here, may be affected by 
PTCD1 dysfunction. Microglia are recognized as a key player in $\mathrm{AD}$ pathogenesis, with many $\mathrm{AD}$ risk genes (e.g., TREM2) being highly and selectively expressed in microglia (Yeh et al., 2017; Hansen et al., 2018; Ulland and Colonna, 2018; Zhou et al., 2018). Most pertinently, chronically impaired energy metabolism and lower ATP levels in microglia have been causally linked to TREM2 mutation and defective microglial handling of $\beta$ amyloid (Ulland et al., 2017). In this context, it is plausible that compromised PTCD1 function plays a role in AD risk by contributing to dysmetabolic low-energy states in microglia.

Complete loss of PTCD1 function is embryonic lethal in mice (Perks et al., 2017, 2018) and loss of function in humans is associated with severe respiratory chain complex defects and heart failure early in life (Taylor et al., 2014). So it is not surprising that the R113W variant in PTCD1 does not present as a severe lossof-function mutation: no effect of the R113W variant on $16 \mathrm{~S}$ rRNA levels and ATP production was observed under glucoserich conditions. Consistent with it conferring a mild loss-offunction phenotype, however, R113W PTCD1 showed a negative effect on OXPHOS and led to a greater reliance on glycolysis when cells were metabolically stressed. We speculate that under normal conditions the R113W variant in PTCD1 does not noticeably impact mitochondrial function. However, during aging or in early stages of $\mathrm{AD}$, this mild loss-of-function variant could impair compensatory responses in energy metabolism that require enhanced mitochondrial translation and ETC function, eventually over years compromising energy supplies, neurotransmission and ultimately, neuronal survival. Independent of acute pathophysiological processes, intermittent metabolic switching has been suggested to positively affect neuroplasticity and brain health and to lower the risk of neurodegeneration in later life (Mattson et al., 2018). The benefits of metabolic switching depend on dynamic mitochondrial biogenesis in neurons, a process that may also be negatively impacted by suboptimal PTCD1 function. Of note, haploinsufficiency of PTCD1 in mice leads to adult-onset metabolic syndrome which in humans is considered another risk factor for AD (Sims-Robinson et al., 2010; Barbagallo and Dominguez, 2014; Neth and Craft, 2017; Perks et al., 2017). Thus it remains possible that PTCD1 confers AD risk in part via effects on tissues outside the brain, which are not studied here.

Although this study identifies PTCD1 as a factor required for mitoribosome assembly and ETC integrity, the precise mechanism by which the R113W substitution alters PTCD1 function remains to be elucidated. Studies focusing on the impact of $\mathrm{R} 113 \mathrm{~W}$ on protein stability and the interaction of PTCD1 with its suggested partners ELAC2, FASTKD2 and RPUSD4 may help explain the increased reliance on glycolysis of cells expressing the variant. Finally, establishment of the physiological relevance of the mild loss-of-function phenotype of the R113W variant will require generation of a mouse model expressing R113W PTCD1, perhaps in conjunction with aging and with crossing to an $\mathrm{AD}$ model.

\section{References}

Aguer C, Gambarotta D, Mailloux RJ, Moffat C, Dent R, McPherson R, Harper ME (2011) Galactose enhances oxidative metabolism and reveals mitochondrial dysfunction in human primary muscle cells. PLoS One 6:e28536.

Albrekkan FM, Kelly-Worden M (2013) Mitochondrial dysfunction and Alzheimer's disease. Open J Endocr Metab Dis 03:14.

Barbagallo M, Dominguez LJ (2014) Type 2 diabetes mellitus and Alzheimer's disease. World J Diabetes 5:889-893.

Barrientos A, Korr D, Barwell KJ, Sjulsen C, Gajewski CD, Manfredi G, Ack- erman S, Tzagoloff A (2003) MTG1 codes for a conserved protein required for mitochondrial translation. Mol Biol Cell 14:2292-2302.

Bélanger M, Allaman I, Magistretti PJ (2011) Brain energy metabolism: focus on astrocyte-neuron metabolic cooperation. Cell Metab 14:724-738.

Bertram L, McQueen MB, Mullin K, Blacker D, Tanzi RE (2007) Systematic meta-analyses of Alzheimer disease genetic association studies: the AlzGene database. Nat Genet 39:17-23.

Brown A, Rathore S, Kimanius D, Aibara S, Bai XC, Rorbach J, Amunts A, Ramakrishnan V (2017) Structures of the human mitochondrial ribosome in native states of assembly. Nat Struct Mol Biol 24:866-869.

Brzezniak LK, Bijata M, Szczesny RJ, Stepien PP (2011) Involvement of human ELAC2 gene product in $3^{\prime}$ end processing of mitochondrial tRNAs. RNA Biol 8:616-626.

Cadonic C, Sabbir MG, Albensi BC (2016) Mechanisms of mitochondrial dysfunction in Alzheimer's disease. Mol Neurobiol 53:6078-6090.

Calvo SE, Mootha VK (2010) The mitochondrial proteome and human disease. Annu Rev Genomics Hum Genet 11:25-44.

Cámara Y, Asin-Cayuela J, Park CB, Metodiev MD, Shi Y, Ruzzenente B, Kukat C, Habermann B, Wibom R, Hultenby K, Franz T, ErdjumentBromage H, Tempst P, Hallberg BM, Gustafsson CM, Larsson NG (2011) MTERF4 regulates translation by targeting the methyltransferase NSUN4 to the mammalian mitochondrial ribosome. Cell Metab 13:527539.

Caspersen C, Wang N, Yao J, Sosunov A, Chen X, Lustbader JW, Xu HW, Stern D, McKhann G, Yan SD (2005) Mitochondrial A $\beta$ : a potential focal point for neuronal metabolic dysfunction in Alzheimer's disease. The FASEB J 19:2040-2041.

Chang S, ran Ma T, Miranda RD, Balestra ME, Mahley RW, Huang Y (2005) Lipid- and receptor-binding regions of apolipoprotein E4 fragments act in concert to cause mitochondrial dysfunction and neurotoxicity. Proc Natl Acad Sci U S A 102:18694-18699.

Chen HK, Ji ZS, Dodson SE, Miranda RD, Rosenblum CI, Reynolds IJ, Freedman SB, Weisgraber KH, Huang Y, Mahley RW (2011) Apolipoprotein $\mathrm{E} 4$ domain interaction mediates detrimental effects on mitochondria and is a potential therapeutic target for Alzheimer disease. J Biol Chem 286: 5215-5221.

Choi M, Chang CY, Clough T, Broudy D, Killeen T, MacLean B, Vitek O (2014) MSstats: an R package for statistical analysis of quantitative mass spectrometry-based proteomic experiments. Bioinformatics 30:25242526.

Cingolani P, Platts A, Wang LL, Coon M, Nguyen T, Wang L, Land SJ, Lu X, Ruden DM (2012) A program for annotating and predicting the effects of single nucleotide polymorphisms, SnpEff: SNPs in the genome of Drosophila melanogaster strain w1118; iso-2; iso-3. Fly 6:80-92.

Clayton DA, Shadel GS (2014a) Isolation of mitochondria from cells and tissues. Cold Spring Harb Protoc 2014:pdb.top074542.

Clayton DA, Shadel GS (2014b) Purification of mitochondria by sucrose step density gradient centrifugation. Cold Spring Harb Protoc 2014:pdb. prot080028.

Cox J, Mann M (2008) MaxQuant enables high peptide identification rates, individualized p.p.b.-range mass accuracies and proteome-wide protein quantification. Nat Biotechnol 26:1367-1372.

Cruchaga C, Nowotny P, Kauwe JS, Ridge PG, Mayo K, Bertelsen S, Hinrichs A, Fagan AM, Holtzman DM, Morris JC, Goate AM; Alzheimer's Disease Neuroimaging Initiative (2011) Association and expression analyses with single-nucleotide polymorphisms in TOMM40 in Alzheimer disease. Arch Neurol 68:1013-1019.

David DC, Hauptmann S, Scherping I, Schuessel K, Keil U, Rizzu P, Ravid R, Dröse S, Brandt U, Müller WE, Eckert A, Götz J (2005) Proteomic and functional analyses reveal a mitochondrial dysfunction in P301L tau transgenic mice. J Biol Chem 280:23802-23814.

DePristo MA, Banks E, Poplin R, Garimella KV, Maguire JR, Hartl C, Philippakis AA, del Angel G, Rivas MA, Hanna M, McKenna A, Fennell TJ, Kernytsky AM, Sivachenko AY, Cibulskis K, Gabriel SB, Altshuler D, Daly MJ (2011) A framework for variation discovery and genotyping using next-generation DNA sequencing data. Nat Genet 43:491-498.

De Strooper B, Karran E (2016) The cellular phase of Alzheimer's disease. Cell 164:603-615.

Devi L, Prabhu BM, Galati DF, Avadhani NG, Anandatheerthavarada HK (2006) Accumulation of amyloid precursor protein in the mitochondrial import channels of human Alzheimer's disease brain is associated with mitochondrial dysfunction. J Neurosci 26:9057-9068. 
Devine MJ, Kittler JT (2018) Mitochondria at the neuronal presynapse in health and disease. Nat Rev Neurosci 19:63-80.

Ferreira IL, Resende R, Ferreiro E, Rego AC, Pereira CF (2010) Multiple defects in energy metabolism in Alzheimer's disease. Curr Drug Targets 11:1193-1206.

Friedman JR, Nunnari J (2014) Mitochondrial form and function. Nature 505:335-343.

Fung S, Nishimura T, Sasarman F, Shoubridge EA (2013) The conserved interaction of C7orf30 with MRPL14 promotes biogenesis of the mitochondrial large ribosomal subunit and mitochondrial translation. Mol Biol Cell 24:184-193.

Hällberg BM, Larsson NG (2014) Making proteins in the powerhouse. Cell Metabolism 20:226-240.

Hansen DV, Hanson JE, Sheng M (2018) Microglia in Alzheimer's disease. J Cell Biol 217:459-472.

Hirai K, Aliev G, Nunomura A, Fujioka H, Russell RL, Atwood CS, Johnson AB, Kress Y, Vinters HV, Tabaton M, Shimohama S, Cash AD, Siedlak SL, Harris PL, Jones PK, Petersen RB, Perry G, Smith MA (2001) Mitochondrial abnormalities in Alzheimer's disease. J Neurosci 21:3017-3023.

Johri A, Beal MF (2012) Mitochondrial dysfunction in neurodegenerative diseases. J Pharmacol Exp Ther 342:619-630.

Jonsson T, Atwal JK, Steinberg S, Snaedal J, Jonsson PV, Bjornsson S, Stefansson H, Sulem P, Gudbjartsson D, Maloney J, Hoyte K, Gustafson A, Liu Y, Lu Y, Bhangale T, Graham RR, Huttenlocher J, Bjornsdottir G, Andreassen OA, Jönsson EG, et al. (2012) A mutation in APP protects against Alzheimer's disease and age-related cognitive decline. Nature 488:96-99.

Joshi AU, Mochly-Rosen D (2018) Mortal engines: mitochondrial bioenergetics and dysfunction in neurodegenerative diseases. Pharmacol Res 138: 2-15.

Kamenetz F, Tomita T, Hsieh H, Seabrook G, Borchelt D, Iwatsubo T, Sisodia S, Malinow R (2003) APP processing and synaptic function. Neuron 37:925-937.

Kapogiannis D, Mattson MP (2011) Disrupted energy metabolism and neuronal circuit dysfunction in cognitive impairment and Alzheimer's disease. Lancet Neurol 10:187-198.

Kerr JS, Adriaanse BA, Greig NH, Mattson MP, Cader MZ, Bohr VA, Fang EF (2017) Mitophagy and Alzheimer's disease: cellular and molecular mechanisms. Trends Neurosci 40:151-166.

Koopman WJ, Distelmaier F, Smeitink JA, Willems PH (2013) OXPHOS mutations and neurodegeneration. EMBO J 32:9-29.

Kotani T, Akabane S, Takeyasu K, Ueda T, Takeuchi N (2013) Human G-proteins, ObgH1 and Mtg1, associate with the large mitochondrial ribosome subunit and are involved in translation and assembly of respiratory complexes. Nucleic Acids Res 41:3713-3722.

Li H, Durbin R (2009) Fast and accurate short read alignment with burrows-wheeler transform. Bioinformatics 25:1754-1760.

Liang WS, Reiman EM, Valla J, Dunckley T, Beach TG, Grover A, Niedzielko TL, Schneider LE, Mastroeni D, Caselli R, Kukull W, Morris JC, Hulette CM, Schmechel D, Rogers J, Stephan DA (2008) Alzheimer's disease is associated with reduced expression of energy metabolism genes in posterior cingulate neurons. Proc Natl Acad Sci U S A 105:4441-4446.

Lin MT, Beal MF (2006) Mitochondrial dysfunction and oxidative stress in neurodegenerative diseases. Nature 443:787-795.

Lustbader JW, Cirilli M, Lin C, Xu HW, Takuma K, Wang N, Caspersen C, Chen X, Pollak S, Chaney M, Trinchese F, Liu S, Gunn-Moore F, Lue LF, Walker DG, Kuppusamy P, Zewier ZL, Arancio O, Stern D, Yan SS, Wu H (2004) ABAD directly links a $\beta$ to mitochondrial toxicity in Alzheimer's disease. Science 304:448-452.

Marroquin LD, Hynes J, Dykens JA, Jamieson JD, Will Y (2007) Circumventing the Crabtree effect: replacing media glucose with galactose increases susceptibility of HepG2 cells to mitochondrial toxicants. Toxicol Sci 97:539-547.

Mattson MP, Gleichmann M, Cheng A (2008) Mitochondria in neuroplasticity and neurological disorders. Neuron 60:748-766.

Mattson MP, Moehl K, Ghena N, Schmaedick M, Cheng A (2018) Intermittent metabolic switching, neuroplasticity and brain health. Nat Rev Neurosci 19:63-80.

McKenna A, Hanna M, Banks E, Sivachenko A, Cibulskis K, Kernytsky A, Garimella K, Altshuler D, Gabriel S, Daly M, DePristo MA (2010) The genome analysis toolkit: a MapReduce framework for analyzing nextgeneration DNA sequencing data. Genome Res 20:1297-1303.

Mi H, Huang X, Muruganujan A, Tang H, Mills C, Kang D, Thomas PD
(2017) PANTHER version 11: expanded annotation data from gene ontology and reactome pathways, and data analysis tool enhancements. Nucleic Acids Res 45:D183-D189.

Moreira PI, Carvalho C, Zhu X, Smith MA, Perry G (2010) Mitochondrial dysfunction is a trigger of Alzheimer's disease pathophysiology. Biochim Biophys Acta 1802:2-10.

Mosconi L, Pupi A, De Leon MJ (2008) Brain glucose hypometabolism and oxidative stress in preclinical Alzheimer's disease. Ann NY Acad Sci 1147:180-195.

Mosconi L, Berti V, Swerdlow RH, Pupi A, Duara R, de Leon M (2010) Maternal transmission of Alzheimer's disease: prodromal metabolic phenotype and the search for genes. Hum Genomics 4:170-193.

Mosconi L, de Leon M, Murray J, E L, Lu J, Javier E, McHugh P, Swerdlow RH (2011) Reduced mitochondria cytochrome oxidase activity in adult children of mothers with Alzheimer's disease. J Alzheimers Dis 27:483-490.

Neth BJ, Craft S (2017) Insulin resistance and Alzheimer's disease: bioenergetic linkages. Front Aging Neurosci 9:345.

Nunomura A, Perry G, Aliev G, Hirai K, Takeda A, Balraj EK, Jones PK, Ghanbari H, Wataya T, Shimohama S, Chiba S, Atwood CS, Petersen RB, Smith MA (2001) Oxidative damage is the earliest event in Alzheimer disease. J Neuropathol Exp Neurol 60:759-767.

Onyango IG, Dennis J, Khan SM (2016) Mitochondrial dysfunction in Alzheimer's disease and the rationale for bioenergetics based therapies. Aging Dis 7:201-214.

Pérez MJ, Jara C, Quintanilla RA (2018) Contribution of tau pathology to mitochondrial impairment in neurodegeneration. Front Neurosci 12: 441.

Perks KL, Ferreira N, Richman TR, Ermer JA, Kuznetsova I, Shearwood AJ, Lee RG, Viola HM, Johnstone VPA, Matthews V, Hool LC, Rackham O, Filipovska A (2017) Adult-onset obesity is triggered by impaired mitochondrial gene expression. Sci Adv 3:e1700677.

Perks KL, Rossetti G, Kuznetsova I, Hughes LA, Ermer JA, Ferreira N, Busch JD, Rudler DL, Spahr H, Schöndorf T, Shearwood AJ, Viola HM, Siira SJ, Hool LC, Milenkovic D, Larsson NG, Rackham O, Filipovska A (2018) PTCD1 is required for $16 \mathrm{~S}$ rRNA maturation complex stability and mitochondrial ribosome assembly. Cell Rep 23:127-142.

Price AL, Patterson NJ, Plenge RM, Weinblatt ME, Shadick NA, Reich D (2006) Principal components analysis corrects for stratification in genome-wide association studies. Nat Genet 38:904-909.

Purcell S, Neale B, Todd-Brown K, Thomas L, Ferreira MA, Bender D, Maller J, Sklar P, de Bakker PI, Daly MJ, Sham PC (2007) PLINK: a tool set for whole-genome association and population-based linkage analyses. Am J Hum Genet 81:559-575.

Rackham O, Filipovska A (2012) The role of mammalian PPR domain proteins in the regulation of mitochondrial gene expression. Biochim Biophys Acta 1819:1008-1016.

Rackham O, Davies SM, Shearwood AM, Hamilton KL, Whelan J, Filipovska A (2009) Pentatricopeptide repeat domain protein 1 lowers the levels of mitochondrial leucine tRNAs in cells. Nucleic Acids Res 37:5859-5867.

Rackham O, Mercer TR, Filipovska A (2012) The human mitochondrial transcriptome and the RNA-binding proteins that regulate its expression. Wiley Interdiscip Rev RNA 3:675-695.

Rhein V, Song X, Wiesner A, Ittner LM, Baysang G, Meier F, Ozmen L, Bluethmann H, Dröse S, Brandt U, Savaskan E, Czech C, Götz J, Eckert A (2009) Amyloid- $\beta$ and tau synergistically impair the oxidative phosphorylation system in triple transgenic Alzheimer's disease mice. Proc Natl Acad Sci U S A 106:20057-20062.

Rorbach J, Boesch P, Gammage PA, Nicholls TJ, Pearce SF, Patel D, Hauser A, Perocchi F, Minczuk M (2014) MRM2 and MRM3 are involved in biogenesis of the large subunit of the mitochondrial ribosome. Mol Biol Cell 25:2542-2555.

Roses AD, Lutz MW, Amrine-Madsen H, Saunders AM, Crenshaw DG, Sundseth SS, Huentelman MJ, Welsh-Bohmer KA, Reiman EM (2010) A TOMM40 variable-length polymorphism predicts the age of late-onset Alzheimer's disease. Pharmacogenomics J 10:375-384

Sanchez MI, Mercer TR, Davies SM, Shearwood AM, Nygård KK, Richman TR, Mattick JS, Rackham O, Filipovska A (2011) RNA processing in human mitochondria. Cell Cycle 10:2904-2916.

Scheltens P, Blennow K, Breteler MM, de Strooper B, Frisoni GB, Salloway S, Van der Flier WM (2016) Alzheimer's disease. Lancet 388:505-517.

Schindelin J, Arganda-Carreras I, Frise E, Kaynig V, Longair M, Pietzsch T, Preibisch S, Rueden C, Saalfeld S, Schmid B, Tinevez JY, White DJ, 
Hartenstein V, Eliceiri K, Tomancak P, Cardona A (2012) Fiji: an opensource platform for biological-image analysis. Nat Methods 9:676-682.

Simoncini C, Orsucci D, Caldarazzo Ienco E, Siciliano G, Bonuccelli U, Mancuso M (2015) Alzheimer's pathogenesis and its link to the mitochondrion. Oxid Med Cell Longev 2015:803942.

Sims R, van der Lee SJ, Naj AC, Bellenguez C, Badarinarayan N, Jakobsdottir J, Kunkle BW, Boland A, Raybould R, Bis JC, Martin ER, Grenier-Boley B, Heilmann-Heimbach S, Chouraki V, Kuzma AB, Sleegers K, Vronskaya M, Ruiz A, Graham RR, Olaso R, et al. (2017) Rare coding variants in PLCG2, ABI3, and TREM2 implicate microglial-mediated innate immunity in Alzheimer's disease. Nat Genet 49:1373-1384.

Sims-Robinson C, Kim B, Rosko A, Feldman EL (2010) How does diabetes accelerate Alzheimer disease pathology? Nat Rev Neurol 6:551-559.

Sperling RA, Aisen PS, Beckett LA, Bennett DA, Craft S, Fagan AM, Iwatsubo T, Jack CR Jr, Kaye J, Montine TJ, Park DC, Reiman EM, Rowe CC, Siemers E, Stern Y, Yaffe K, Carrillo MC, Thies B, Morrison-Bogorad M, Wagster MV, Phelps CH (2011) Toward defining the preclinical stages of Alzheimer's disease: recommendations from the national institute on aging-Alzheimer's association workgroups on diagnostic guidelines for Alzheimer's disease. Alzheimers Dement 7:280-292.

Sultana R, Perluigi M, Newman SF, Pierce WM, Cini C, Coccia R, Butterfield DA (2010) Redox proteomic analysis of carbonylated brain proteins in mild cognitive impairment and early Alzheimer's disease. Antioxid Redox Signal 12:327-336.

Sun N, Youle RJ, Finkel T (2016) The mitochondrial basis of aging. Mol Cell 61:654-666.

Swerdlow RH, Burns JM, Khan SM (2014) The Alzheimer's disease mitochondrial cascade hypothesis: progress and perspectives. Biochim Biophys Acta 1842:1219-1231.

Taylor RW, Pyle A, Griffin H, Blakely EL, Duff J, He L, Smertenko T, Alston CL, Neeve VC, Best A, Yarham JW, Kirschner J, Schara U, Talim B, Topaloglu H, Baric I, Holinski-Feder E, Abicht A, Czermin B, Kleinle S, et al. (2014) Use of whole-exome sequencing to determine the genetic basis of multiple mitochondrial respiratory chain complex deficiencies. JAMA 312:68-77.

Trougakos IP, Lourda M, Antonelou MH, Kletsas D, Gorgoulis VG, Papassideri IS, Zou Y, Margaritis LH, Boothman DA, Gonos ES (2009) Intracellular clusterin inhibits mitochondrial apoptosis by suppressing p53activating stress signals and stabilizing the cytosolic Ku70-bax protein complex. Clin Cancer Res 15:48-59.

Tuppen HA, Blakely EL, Turnbull DM, Taylor RW (2010) Mitochondrial DNA mutations and human disease. Biochim Biophys Acta 1797: $113-128$.

Ulland TK, Colonna M (2018) TREM2: a key player in microglial biology and Alzheimer disease. Nat Rev Neurol 14:667-675.
Ulland TK, Song WM, Huang SC, Ulrich JD, Sergushichev A, Beatty WL, Loboda AA, Zhou Y, Cairns NJ, Kambal A, Loginicheva E, Gilfillan S, Cella M, Virgin HW, Unanue ER, Wang Y, Artyomov MN, Holtzman DM, Colonna M (2017) TREM2 maintains microglial metabolic fitness in Alzheimer's disease. Cell 170:649-663.e13.

Van der Auwera GA, Carneiro MO, Hartl C, Poplin R, Del Angel G, LevyMoonshine A, Jordan T, Shakir K, Roazen D, Thibault J, Banks E, Garimella KV, Altshuler D, Gabriel S, DePristo MA (2013) From FastQ data to high confidence variant calls: the genome analysis toolkit best practices pipeline. Curr Protoc Bioinformatics 43:11.10.1-33.

Wang X, Su B, Lee HG, Li X, Perry G, Smith MA, Zhu X (2009) Impaired balance of mitochondrial fission and fusion in Alzheimer's disease. J Neurosci 29:9090-9103.

Wanschers BF, Szklarczyk R, Pajak A, van den Brand MA, Gloerich J, Rodenburg RJ, Lightowlers RN, Nijtmans LG, Huynen MA (2012) C7orf30 specifically associates with the large subunit of the mitochondrial ribosome and is involved in translation. Nucleic Acids Res 40:4040-4051.

Williams TI, Lynn BC, Markesbery WR, Lovell MA (2006) Increased levels of 4-hydroxynonenal and acrolein, neurotoxic markers of lipid peroxidation, in the brain in mild cognitive impairment and early Alzheimer's disease. Neurobiol Aging 27:1094-1099.

Yeh FL, Hansen DV, Sheng M (2017) TREM2, microglia, and neurodegenerative diseases. Trends Mol Med 23:512-533.

Zhang H, Kim JK, Edwards CA, Xu Z, Taichman R, Wang CY (2005) Clusterin inhibits apoptosis by interacting with activated bax. Nat Cell Biol 7:909-915.

Zhang Y, Chen K, Sloan SA, Bennett ML, Scholze AR, O'Keeffe S, Phatnani HP, Guarnieri P, Caneda C, Ruderisch N, Deng S, Liddelow SA, Zhang C, Daneman R, Maniatis T, Barres BA, Wu JQ (2014) An RNA-sequencing transcriptome and splicing database of glia, neurons, and vascular cells of the cerebral cortex. J Neurosci 34:11929-11947.

Zhou Y, Ulland TK, Colonna M (2018) TREM2-dependent effects on microglia in Alzheimer's disease. Front Aging Neurosci 10:202.

Zick M, Rabl R, Reichert AS (2009) Cristae formation: linking ultrastructure and function of mitochondria. Biochim Biophys Acta 1793:5-19.

Zilberter Y, Zilberter M (2017) The vicious circle of hypometabolism in neurodegenerative diseases: ways and mechanisms of metabolic correction. J Neurosci Res 95:2217-2235.

Zuchero YJ, Chen X, Bien-Ly N, Bumbaca D, Tong RK, Gao X, Zhang S, Hoyte K, Luk W, Huntley MA, Phu L, Tan C, Kallop D, Weimer RM, Lu Y, Kirkpatrick DS, Ernst JA, Chih B, Dennis MS, Watts RJ (2016) Discovery of novel blood-brain barrier targets to enhance brain uptake of therapeutic antibodies. Neuron 89:70-82. 